\title{
Low molecular weight organic acids in aerosol particles from Rondônia, Brazil, during the biomass-burning, transition and wet periods
}

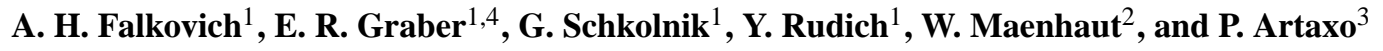 \\ ${ }^{1}$ Department of Environmental Sciences, Weizmann Institute, Rehovot 76100, Israel \\ ${ }^{2}$ Department of Analytical Chemistry, Institute for Nuclear Sciences, Ghent University, Proeftuinstraat 86, B-9000 Gent, \\ Belgium \\ ${ }^{3}$ Institute of Physics, University of São Paulo (IFUSP), Rua do Matão, Travessa R, 187, CEP 05508-900 São Paulo, Brazil \\ ${ }^{4}$ Permanent affiliation: Institute of Soil, Water and Environmental Sciences, The Volcani Center, ARO, Bet Dagan 50250, \\ Israel
}

Received: 20 September 2004 - Published in Atmos. Chem. Phys. Discuss.: 28 October 2004

Revised: 23 February 2005 - Accepted: 1 March 2005 - Published: 10 March 2005

\begin{abstract}
Particles from biomass burning and regional haze were sampled in Rondônia, Brazil, during dry, transition and wet periods from September to November 2002, as part of the LBA-SMOCC (Large-Scale Biosphere-Atmosphere Experiment in Amazonia - Smoke, Aerosols, Clouds, Rainfall, and Climate) field campaign. Water soluble organic and inorganic compounds in bulk (High Volume and Stacked Filter Unit sampler) and size-resolved (Micro Orifice Uniform Deposit Impactor - MOUDI) smoke samples were determined by ion chromatography. It was found that low molecular weight polar organic acids account for a significant fraction of the water soluble organic carbon (WSOC) in biomass burning aerosols $\left(\mathrm{C}_{2}-\mathrm{C}_{6}\right.$ dicarboxylic acids reached up to $3.7 \%$ and one-ring aromatic acids reached up to $2 \%$ of fine fraction WSOC during burning period). Short dicarboxylic $\left(\mathrm{C}_{2}-\mathrm{C}_{6}\right)$ acids are dominated by oxalic acid followed by malonic and succinic acids. The largest ionic species is ammonium sulfate (60-70\% of ionic mass). It was found that most of the ionic mass is concentrated in submicrometer-sized particles. Based on the size distribution and correlations with $\mathrm{K}^{+}$, a known biomass burning tracer, it is suggested that many of the organic acids are directly emitted by vegetation fires. Concentrations of dicarboxylic acids in the front and back filters of high volume sampler were determined. Based on these measurements, it was concluded that in the neutral or slightly basic smoke particles typical of this region, dicarboxylic acids are mostly confined to the particulate phase. Finally, it is shown that the distribution of water soluble species
\end{abstract}

Correspondence to: Y. Rudich

(yinon.rudich@weizmann.ac.il) shifts to larger aerosols sizes as the aerosol population ages and mixes with other aerosol types in the atmosphere.

\section{Introduction}

There is a recent consensus that water soluble organic carbon (WSOC) compounds in atmospheric particles may play a significant role in the formation of cloud condensation nuclei (CCN) (Laaksonen et al., 1998; Yu, 2000; Charlson et al., 2001; Nenes et al., 2002). As cloud condensation nuclei $(\mathrm{CCN})$ are directly responsible for modulating cloud microphysical properties and for influencing cloud radiative properties, understanding the origin and nature of WSOCcontaining aerosol activity has taken on new importance (Kaufman and Fraser, 1997; Ramanathan et al., 2001; Kaufman et al., 2002; Roberts et al., 2003). This work is a part of SMOCC (Smoke Aerosols, Clouds, Rainfall and Climate), a project under the framework of the Large-Scale AtmosphereBiosphere Experiment in Amazonia (LBA), aiming at investigating the connection between the concentration and chemical composition of biomass burning aerosols, resultant changes in the effective radii of cloud droplets, and the climatic consequences of the resulting perturbation of cloud physics. A comprehensive description and discussion of the SMOCC campaign and results appear in a special issue of $\mathrm{ACP}$, of which this article is part.

One of the major global sources for WSOC-containing aerosol is biomass burning, wherein WSOC components have been found to account for $45-75 \%$ of the total aerosol carbon mass (Graham et al., 2002; Mayol-Bracero et al.,

(C) 2005 Author(s). This work is licensed under a Creative Commons License. 
2002). As carbonaceous material constitutes as much as 70 90\% of the total aerosol mass (Cachier et al., 1995; Andreae and Crutzen, 1997; Yamasoe et al., 2000), it is clear that the amount of WSOC emitted to the atmosphere due to biomass burning is globally important. The WSOC in biomass burning particles contributes to their CCN activity, and hence to their global climatic effects (Sherwood, 2002; Andreae et al., 2004). WSOC derived from smoke aerosols may also participate in aqueous phase chemical reactions occurring in droplets nucleated by smoke particles.

The organic components of biomass burning aerosols consist of a complex mixture of compounds reflecting a wide range of molecular structures, physical properties and chemical reactivities (Andreae and Merlet, 2001). Although a few recent studies have concentrated on identification and quantification of water soluble components of smoke particles (Graham et al., 2002; Mayol-Bracero et al., 2002; Gao et al., 2003), typically less than $10 \%$ by mass of WSOCs has been identified successfully (Graham et al., 2002; Gao et al., 2003). Most previous studies concentrated on characterizing bulk samples collected during biomass burning activity. Data about the distribution of WSOC in the different particle sizes, and the changes in that distribution occurring during the transition from the dry (biomass burning) season to the wet (background clean conditions) season are scarce. The water soluble organic species include both highly dissociated species, such as organic acids and salts, as well as weaker acids and humic-like species, which are less ionized and can be surface active (Hoffer et al., 2004). There are also soluble, non ionic species such as anhydrous sugars ( $\mathrm{Si}$ moneit et al., 1999; Simoneit, 2002). In this study, we focus on characterizing temporal changes in the concentration and size distribution of the highly dissociated, low molecular weight (LMW) organic acids that are found in relatively fresh plumes of smoke particles from vegetation burning in Brazil.

Gao et al. (2003) measured WSOC concentrations in biomass burning particles collected from savanna fires in southern Africa, reporting abundances of 7 organic acids measured in their anionic form by ion chromatography, including acetate, formate, oxalate, malonate, succinate, glutarate and gluconate. Seven carbohydrates were also quantified by electrospray ionization-ion trap mass spectrometry coupled with ion exclusion chromatography with pulsed amperometric detection. In general, the organic acids measured represented less than $5 \%$ of the total aerosol mass, while the carbohydrate mass fraction varied from about $15 \%$ to only a few percent. The most abundant organic acid found in the study was tentatively identified as gluconic acid (average mass fraction 0.0045), with the other mono- and dicarboxylic acids making even smaller contributions. Levoglucosan, while reported to be the most abundant carbohydrate with an average mass fraction of 0.033 , was present only during the smoldering phases. For samples collected in October 1999 in Brazil (at the same site as used in the current study), Mayol-Bracero et al. (2002) employed an anion exchange HPLC/IC technique (Decesari et al., 2000) to separate WSOCs into three compound classes: neutral, monoand dicarboxylic acids, and polycarboxylic acids. They found that the acid fractions represented about $51 \%$ of the WSOC fraction, but did not further speciate the compounds. In a companion paper (Graham et al., 2002), levoglucosan was reported to account for 1-6\% of total carbon, and 2$7 \%$ of WSOC. Altogether, Graham et al. (2002) identified by GC/MS between 9 to $14 \%$ of the WSOC fraction, including a number of aliphatic di- and tricarboxylic acids, aliphatic oxo/hydroxyacids, and aromatic compounds. The simple di- and tricarboxylic aliphatic acids were found to make up about 1$2 \%$ of the WSOC, on average, with oxalic acid being most abundant, followed by malonic and succinic acids. Components in the other compound classes were, in general, even less abundant. For aerosols from the 1997 Indonesian forest fires, Narukawa et al. (1999) also reported a homologous series of dicarboxylic acids, dominated by oxalic acid, and followed in abundance by malonic and succinic acid. In their work, these dicarboxylic fractions represented $2-8 \%$ of the WSOC. None of these papers report relative distributions of these compounds as a function of aerosol size, season, or day/night interval.

Considering the foregoing, it is evident that more comprehensive datasets involving chemical characterization of the WSOC fraction of biomass burning aerosols are needed. In particular, it is essential to characterize changes in WSOC composition with seasonal changes in biomass burning, and differences in WSOC components as a function of aerosol size. Considering its importance, this study concentrates on the ionic WSOC chemical composition of biomass burning aerosols collected day and night throughout a ten-week interval from the peak of the 2002 dry (biomass burning) season into the following wet season in Rondônia, Brazil, with particular attention to chemical differences between sizeresolved aerosol samples. It is hoped that such detailed data, besides helping to elucidate the potential CCN activity played by such aerosols, will provide essential input for climate models that aim to evaluate large scale meteorological and climatological effects of biomass burning. Recent detailed analysis of the gas phase precursors and gas/aerosol partitioning processes have shown that LMW polar organic acids should be incorporated in thermodynamic models to accurately predict inorganic aerosol composition (Trebs et al., 2005). Detailed chemical characterization of the ionic WSOC fraction can also provide the basis for thermodynamic models describing water uptake by aerosol particles in haze and cloudy conditions, thus shedding light on smoke aerosol effect on climate. 


\section{Experimental}

\subsection{Sampling}

Smoke particles were sampled in the state of Rondônia, Brazil, at a pasture site (Fazenda Nossa Senhora Aparecida (FNS); $10^{\circ} 45^{\prime} 50^{\prime \prime} \mathrm{S}, 62^{\circ} 21^{\prime} 36^{\prime \prime} \mathrm{W}, 284 \mathrm{~m}$ above sea level), from 8 September to 11 November 2002, as a part of the LBA-SMOCC (Large-Scale Biosphere-Atmosphere Experiment in Amazonia - Smoke, Aerosols, Clouds, Rainfall, and Climate) campaign. According to meteorological conditions, the sampling period is subdivided into dry (intense burning; 8 September to 7 October), transition (8 October to 29 October) and wet (30 October to 11 November) periods. A detailed description of the site is given in Kirkman et al. (2002). Aerosol samples were obtained from regionally emitted biomass burning plumes for periods of time ranging from 12 to $72 \mathrm{~h}$ per sample (Depending on aerosol loadings. Sampling times are similar for all samplers), using two filter samplers and one cascade impactor:

- Stacked Filter Unit (SFU) sampler that separates coarse $(10>d>2.0 \mu \mathrm{m}$, where $d$ is aerodynamic diameter) and fine particles $(d<2.0 \mu \mathrm{m})$ by sequential filtration on 8.0 and $0.4 \mu \mathrm{m}$ pore-size Nuclepore ${ }^{\circledR}$ polycarbonate filters (Whatman, $47 \mathrm{~mm}$ diameter), with a flow rate of 10 $151 / \mathrm{min}$.

- High Volume (HiVol) dichotomous sampler that separates fine $(d<2.5 \mu \mathrm{m})$ from coarse particles $(d>2.5 \mu \mathrm{m})$ with a flow rate of $300 \mathrm{l} / \mathrm{min}$ for the fine fraction and 301/min for the coarse fraction. For both size fractions, the particles were collected on a front/back tandem system of quartz fiber filters $(102 \mathrm{~mm}$ diameter, Pallflex $\AA$, Pall Corporation; prebaked for $24 \mathrm{~h}$ at $550^{\circ} \mathrm{C}$ ). The use of a tandem filter system allows estimating possible artifacts in particulate organic matter determination due to adsorption of gaseous organic compounds by filters (Novakov et al., 1997; Turpin et al., 2000). It is assumed that the front quartz filter collects aerosol particles with close to $100 \%$ efficiency, while gaseous organics adsorb on both filters evenly.

- Micro Orifice Uniform Deposit Impactor (MOUDI) (model 110, MSP Corporation, Minneapolis, USA) was employed for collection of size-resolved smoke particles, flow rate of $25-301 / \mathrm{min}$. Aerosols were separated into 9 fractions with calibrated aerodynamic cutoffs of $18,10.0,3.2,1.8,1.0,0.56,0.33,0.175$ and $0.093 \mu \mathrm{m}$. Sampling was carried out on Nuclepore ${ }^{\circledR}$ polycarbonate (Whatman) filters with $47 \mathrm{~mm}$ diameter, and a Teflon back-up filter was used for collection of the particles $<0.093 \mu \mathrm{m}$.

Flow rates and sampling volumes were determined by Hastings mass flowmeters for the SFU and MOUDI samples. The loaded filters were placed immediately in clean plastic Petrislide dishes (for SFU and MOUDI samples) or in prebaked aluminum foil (for the $\mathrm{HiVol}$ samples) and stored at $-25^{\circ} \mathrm{C}$ until analysis. Filter blanks were obtained using the same loading and unloading procedure as for normal filters but with a sampling time of only $15 \mathrm{~s}$.

\subsection{Possible sampling artifacts}

When sampling for OC and WSOC on a quartz fiber filter, the following positive artifacts may occur: (1) Adsorption of volatile organic compounds (VOCs) by the filter and accumulated aerosol particles, (2) adsorption of the gas-phase component of semi-volatile organic compounds (SVOCs) by the filter and by accumulated aerosol particles. A possible negative artifact (3) may be evaporation/sublimation of particulate organic compounds collected on the filter.

In undenuded sampling with a front and back filter, the particulate-phase OC is normally obtained by subtracting OC on the back filter from that on the front filter. A number of assumptions are made when doing this correction: (1) mass/filter area amount of each VOC and SVOC adsorbed from the gas phase is equal for front and backup filters; (2) the gas adsorption capacity of the front and backup filter are equal; and (3) SVOCs observed on the backup filter do not derive from evaporation of particles collected on the front filter (Mader et al., 2003). When dealing with artifacts for individual compounds, the above mentioned positive artifact (2) and the negative artifact (3) still exist, but (1) does not. It is possible to use back-to-front filter ratios to evaluate sampling artifacts and to assess the semivolatility of species (Novakov et al., 1997; Turpin et al., 2000; Limbeck et al., 2001).

When sampling on a Nuclepore substrate, as for the SFU sampler and MOUDI impactor, positive artifacts are reduced to gas phase adsorption by collected aerosol particles themselves, because the substrate adsorbs substantially less than quartz fiber filter. A negative artifact due to evaporation/sublimation may still exist for the SFU sampler and MOUDI impactor due to the lower pressures inside the samplers at the lowest stages. However, in a paper summarizing the results of particulate matter (PM) measurements during the INTERCOMP2000 intercomparison experiment (Hitzenberger et al., 2004), concentrations obtained by SFU with Nuclepore substrate and by MOUDI impactor do not deviate significantly from the average of concentrations obtained by numerous different methods.

Considering the foregoing, it can be expected that concentrations obtained from the quartz fiber HiVol samples will be overestimated relative to those obtained from the SFU and MOUDI samples collected on Nuclepore, as was also found by Salma et al. (2004). In such a case, the back-to-front filter ratios of the HiVol samples can be used to assess the extent of overestimation, and species volatility. A detailed intercomparison between the different sampling instrumentation deployed in the SMOCC field campaign is beyond the scope 
Table 1. Elution gradient used for anion chromatography.

\begin{tabular}{llll}
\hline Time (min) & water & $0.4 \mathrm{mM} \mathrm{NaOH}$ & $25 \mathrm{mM} \mathrm{NaOH}$ \\
\hline Initial & 80 & 20 & 0 \\
2.0 & 80 & 20 & 0 \\
8.5 & 0 & 100 & 0 \\
14.0 & 0 & 43 & 57 \\
17.0 & 0 & 33 & 67 \\
17.1 & 0 & 0 & 100 \\
23.0 & 0 & 0 & 100 \\
\hline
\end{tabular}

of this paper and will be discussed in other papers of the ACP SMOCC special issue (Maenhaut et al., 2004; Claeys et al., 2005 ${ }^{1}$; Schkolnik et al., 2005; Trebs et al., 2005; Decesari et al., $\left.2005 \mathrm{a}^{2}, \mathrm{~b}^{3}\right)$.

\subsection{Ion chromatography (IC) analysis}

Inorganic and organic ionic species were quantified by ion chromatography after extraction of filters with water. The extraction and analytical procedures have been thoroughly validated (Falkovich et al., 2004).

\subsection{Materials}

The following chemicals and standards were used: (1) Sodium hydroxide $50 \%(\mathrm{w} / \mathrm{w})$ solution, J. T. Baker, Phillipsburg, NJ, USA; (2) Anionen multi-element standard I $\left(\mathrm{F}^{-}\right.$, $\mathrm{PO}_{4}^{3-}$ and $\left.\mathrm{Br}^{-}, 1000 \mathrm{mg} / \mathrm{l}\right)$, Anionen multi-element standard II $\left(\mathrm{Cl}^{-}, \mathrm{NO}_{3}^{-}, \mathrm{SO}_{4}^{2-}, 1000 \mathrm{mg} / \mathrm{l}\right)$, Nitrite standard solution $\left(\mathrm{NO}_{2}^{-}, 1000 \mathrm{mg} / \mathrm{l}\right)$ and Sodium iodide GR $(99.5 \%)$, Merck, Darmstadt, Germany; (3) Six Cation - II Standard, Dionex, Sunnyvale, CA; (4) Organic acid and anion standards, Riedel-de Haen, Seelze, Germany, Fluka Chemie, Switzerland, Sigma-Aldrich Chemie Gmbh, Steinheim, Germany, and Supelco, Bellefonte, PA.

\footnotetext{
${ }^{1}$ Claeys, M., Pashynska, V., Kourtchev, I., Vermeylen, R., Cafmeyer, J., Artaxo, P., and Maenhaut, W.: Levoglucosan and selected polar organic compounds in boundary layer aerosols during the LBA/CLAIRE/SMOCC-2002 campaign, in preparation, 2005.

${ }^{2}$ Decesari, S., Fuzzi, S., Maenhaut, W., Tagliavini, E., Falkovich, A. H., Schkolnik, G., Rudich, Y., Guyon, P., Claeys, M., and Artaxo, P.: Apportionment of particulate OC into individual compounds and chemical classes in carbonaceous aerosol samples collected during the dry-to-wet season transition in Rondônia, Brazil, in preparation, 2005a.

${ }^{3}$ Decesari, S., Fuzzi, S., Maenhaut, W., Tagliavini, E., Falkovich, A. H., Rudich, Y., Guyon, P., Mayol-Bracero, O., Fisch, G., Claeys, M., and Artaxo, P.: Inorganic and organic composition of size-segregated aerosols in the dry-to-wet season transition, in preparation, 2005b.
}

\subsection{Sample preparation}

Aqueous aerosol extracts were prepared by shaking a portion of the loaded filters vigorously for $15 \mathrm{~min}$ in Nanopure water $(18.0 \mathrm{M} \Omega-\mathrm{cm})$ in capped glass vials. Sample solutions were left for an hour in the dark and then were filtered with prewashed GHP Acrodisk ${ }^{\circledR}$ (Gelman, $0.45 \mu \mathrm{m}$ ) syringe filters. A whole MOUDI filter or a half of SFU filter were extracted once with $4 \mathrm{ml}$ of water; a quarter of a HiVol filter was extracted twice with $5 \mathrm{ml}$ portions of water.

\subsection{Ion chromatography conditions}

The IC analysis was carried out using a Varian ProStar HPLC system equipped with a Dionex ED50 electrochemical detector at isothermal $\left(24^{\circ} \mathrm{C}\right)$ conditions. Anions were determined using a Dionex AS11 analytical column and ASRSUltra suppressor in autosuppression mode. For simultaneous separation of inorganic and short-chain $\left(\mathrm{C}_{1}-\mathrm{C}_{9}\right)$ organic anions, gradient elution by $0.4-25 \mathrm{mM} \mathrm{NaOH}(2 \mathrm{~mL} / \mathrm{min})$ was employed (Table 1). Cations were determined using a Dionex CS12 column and CSRS-Ultra suppressor in autosuppression mode with $20 \mathrm{mM}$ methanesulfonic acid (MSA) as an eluent $\left(1 \mathrm{ml} \mathrm{min}^{-1}\right)$. All ions were quantified against standard calibration curves. Concentration data are given as mass concentrations in air corrected to standard temperature and pressure, STP $(298 \mathrm{~K}, 1000 \mathrm{hPa})$. The analyzed ionic species are listed in Table 2. Since all organic acids listed in Table 2 have been measured as their anionic forms, when discussing organic acids we refer to their anionic mass concentrations.

In this study, 34 SFU samples (19 from the dry period, 7 from the transition and 8 from the wet period) and $22 \mathrm{HiVol}$ samples ( 16 from the dry period, 5 from the transition and 1 from the wet period) were analyzed. Selected MOUDI samples (nine filter membranes each) were analyzed in this study: three MOUDI samples collected during the dry period: MDRO37 (23 September), MDRO39 (25 September) and MDRO40 (28 September), about $24 \mathrm{~h}$ sampling interval for each; two MOUDI samples collected during the transition period: MDRO53 (16-18 October, $38 \mathrm{~h}$ ) and MDRO54 (1820 October, $44 \mathrm{~h}$ ); and one MOUDI sample collected during the wet period: MDRO60b (6-10 November, $99 \mathrm{~h}$ ). It is noted that while rain was very rare during the dry period, a $20 \mathrm{~mm}$ rain period occurred on the morning of 28 September (during the MDRO40 sampling).

\subsection{Aerosol mass concentration (Particulate Mass - PM) and Water Soluble Organic Carbon (WSOC) determi- nation}

Organic carbon, elemental carbon and water-soluble organic carbon (WSOC) in the aerosol were determined by the Department of Analytical Chemistry, Institute for Nuclear 
Table 2. Organic and inorganic ions determined by ion chromatography in smoke samples.

\begin{tabular}{lll}
\hline Inorganic & cations & $\mathrm{Na}^{+}, \mathrm{NH}_{4}^{+}, \mathrm{K}^{+}, \mathrm{Mg}^{++}, \mathrm{Ca}^{++}$ \\
& anions $^{\mathrm{a}}$ & $\mathrm{Cl}^{-}, \mathrm{NO}_{2}^{-}, \mathrm{NO}_{3}^{-}, \mathrm{SO}_{4}^{2-}, \mathrm{PO}_{4}^{3-}, \mathrm{CH}_{3} \mathrm{SO}_{3}^{-}(\mathrm{MSA})$ \\
\hline & monocarboxylic (MCA) & $\begin{array}{l}\text { formic, acetic, glycolic, glyceric, lactic, } \\
\text { pyruvic, glyoxylic, valeric, trichloracetic, threonic }\end{array}$ \\
& dicarboxylic (DCA) & $\begin{array}{l}\text { oxalic, malonic } \\
\text { Anions of hydroxymalonic, methylmalonic, maleic, } \\
\text { malic, succinic, methylsuccinic, dihydroxysuccinic, glutaric, } \\
\text { adipic, 2-hydroxyglutaric, tartaric, fumaric, azelaic }\end{array}$ \\
& citric, tricarballylic \\
tricarboxylic (TCA) & phthalic, syringic, 3-hydroxybenzoic, 4-hydroxybenzoic, vanillic, isovanillic \\
& aromatic &
\end{tabular}

${ }^{a} \mathrm{CO}_{3}^{2-}$ can not be determined by our anion chromatography system;

$\mathrm{b}$ Malonate concentration is underestimated because of its poor separation from the carbonate peak.

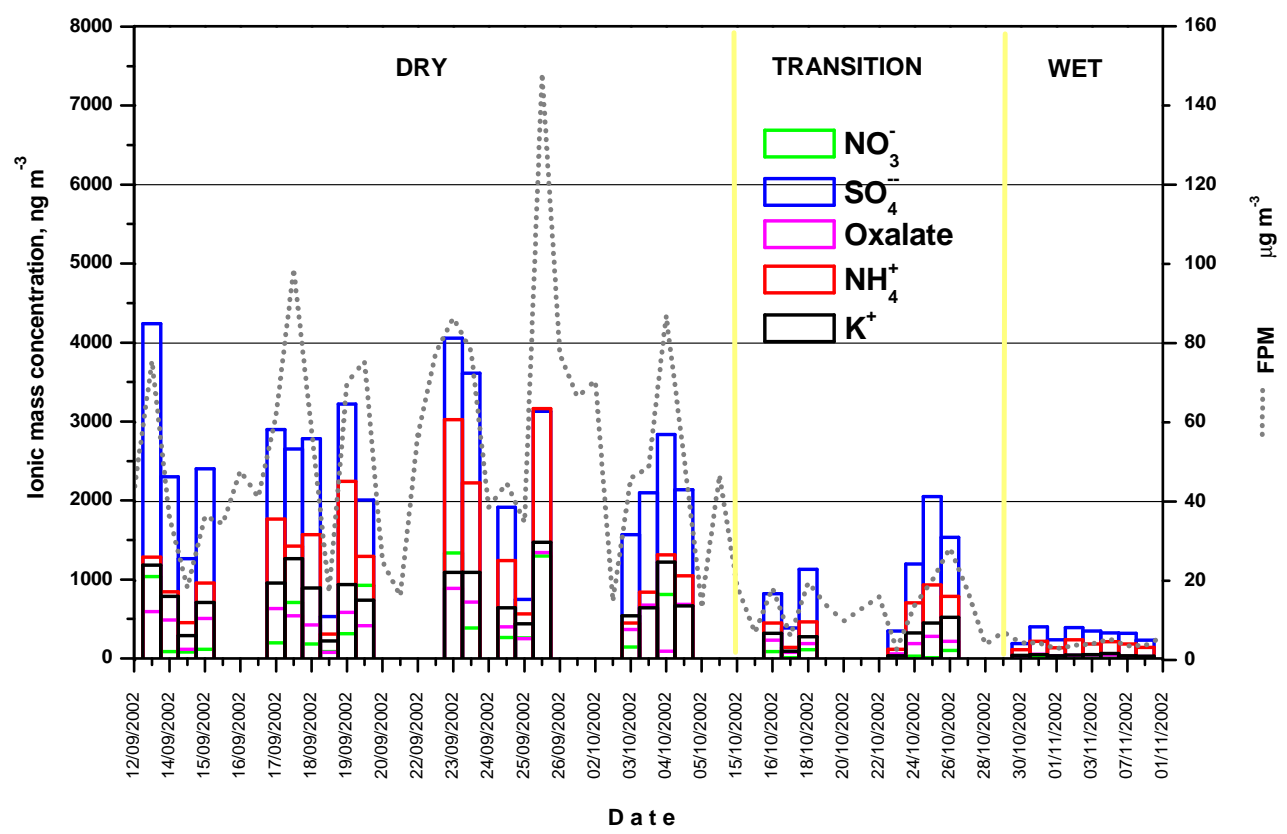

Fig. 1. Mass concentrations of the five major ions in the fine size fraction of SFU aerosol samples collected at FNS, Rondônia, Brazil, September-November, 2002. The dashed line is the fine particle mass concentration (FPM).

Sciences, Ghent University. The detailed technique is published elsewhere (Chi and Maenhaut, 2005 ${ }^{4}$ ).

Aerosol mass concentrations were determined for each size bin using the SFU and MOUDI samples. It was measured gravimetrically in a Mettler electronic microbalance with 1 microgram sensitivity. Before weighing, the Nuclepore filters were left for $24 \mathrm{~h}$ under radioactive sources for static electricity removal, and under a constant temperature of $18^{\circ} \mathrm{C}$ and $50 \%$ relative humidity. Each filter was weighed 3 times on different days, and the average of the three masses

\footnotetext{
${ }^{4}$ Chi, X. and Maenhaut, W.: Organic carbon, elemental carbon and water-soluble organic carbon in the PM2.5 aerosol at different sampling sites, Atmos. Chem. Phys. Discuss., in preparation, 2005.
}

reported. The air volume through the filters was measured using precision mass flowmeters.

\section{Results}

In general, throughout the entire sampling interval, potassium, ammonium, nitrate, sulfate and $\mathrm{C}_{2}-\mathrm{C}_{6}$ dicarboxylic acids (DCA) accounted for more than $92 \%$ of the total ionic mass concentration of the smoke particles. The following results and discussion will focus mainly on temporal changes in concentrations of the ions and on their size distributions, with emphasis on the $\mathrm{C}_{2}-\mathrm{C}_{6}$ DCA (including straight-chain, branched, keto- and hydroxyl- derivatives, as 
Table 3. Selected particulate mass concentrations $\left(\mu \mathrm{g} \mathrm{m}^{-3}\right)$ and ionic mass concentrations $\left(\mathrm{ng} \mathrm{m}^{-3}\right)$ identified by IC in aqueous extracts of SFU aerosol samples from FNS, Brazil, 2002.

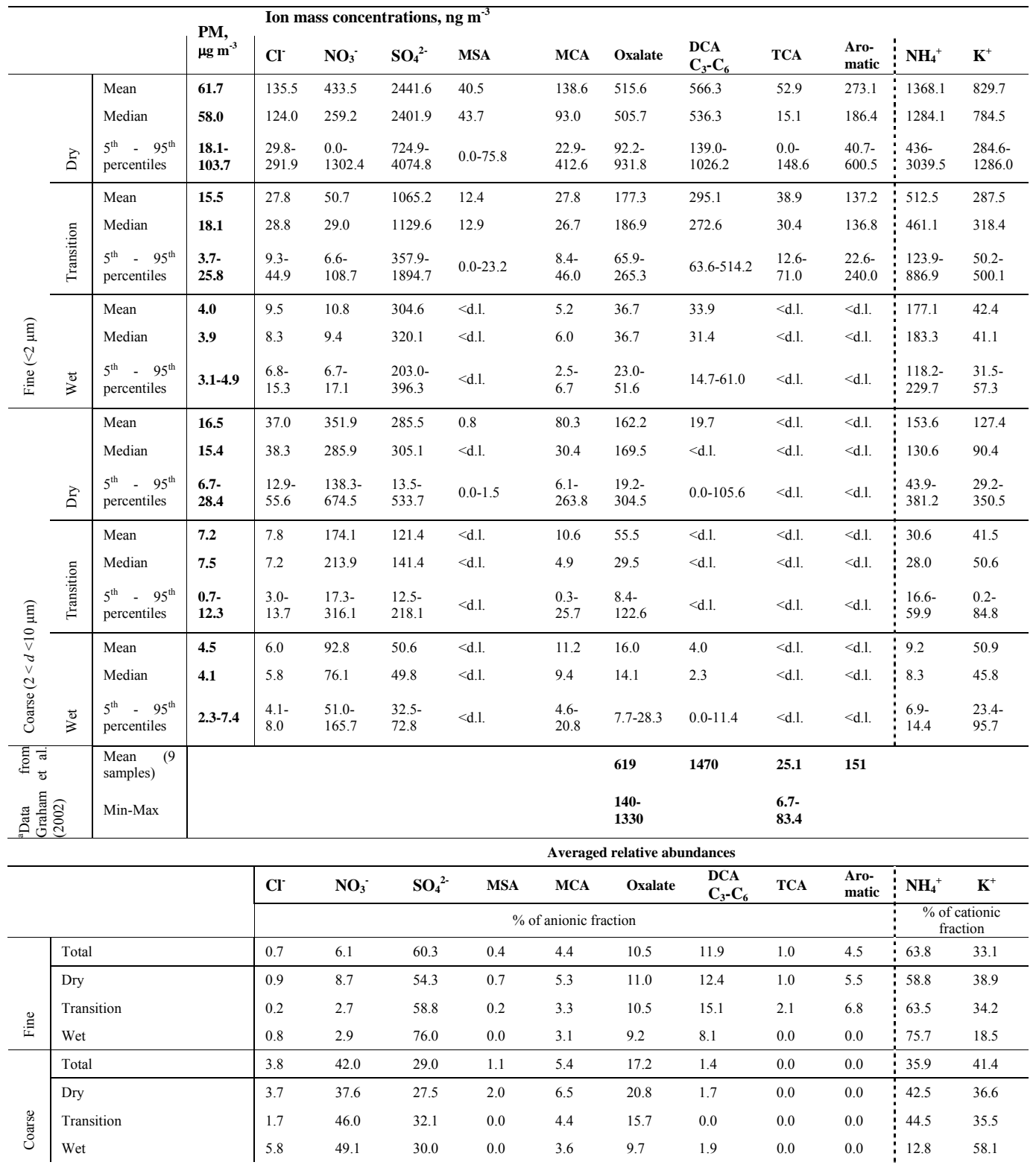

a The organic acid mass concentrations were measured by gas chromatography - mass spectrometry (GC/MS) at the same FNS pasture site during dry and transition periods, 1-29 October 1999, as a part of LBA experiment.

listed in Table 2). The results are presented according to the sampling devices. Additional information on the inorganic and organic - both ionic and neutral - composition of bulk and size-resolved aerosols sampled during the burning period and dry-to-wet season transition appears in further publications related to the SMOCC campaign (Maenhaut et al., 2004; Claeys et al., 2005 ${ }^{1}$; Schkolnik et al., 2005; Trebs et al., 2005; Decesari et al., 2005a ${ }^{2}, b^{4}$ ).

\subsection{Stacked filter unit (SFU) data}

The concentrations of particulate mass (PM) ranged from 2.7 to $148.1 \mu \mathrm{g} \mathrm{m}^{-3}$ for the fine size fraction (FPM) and from 0.5 to $31.1 \mu \mathrm{g} \mathrm{m}^{-3}$ for the coarse size fraction (see Table 3 for detailed data). The highest FPM concentrations were measured during the dry period, when biomass burning emissions were most intense. In the transition and wet periods, FPM concentrations were considerably smaller. 


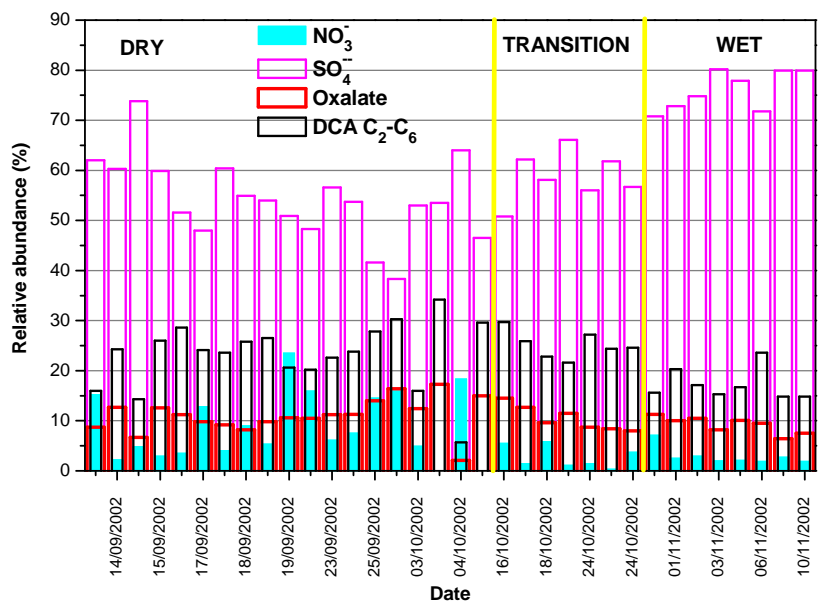

Fig. 2. Relative abundances of anions in the SFU fine mode anionic fraction.

The temporal variations in FPM concentration are shown in Fig. 1. Throughout the sampling interval, mass concentrations of the five major ions (potassium, ammonium, nitrate, sulfate and oxalate) followed similar temporal trends to the FPM (Fig. 1).

The mass concentrations and relative abundances $(\%)$ of ions determined in the SFU samples are given in Table 3. Temporal variations in the relative abundances of nitrate, sulfate, $\mathrm{C}_{3}$ to $\mathrm{C}_{6}$ DCA (lumped together) and oxalate in the fine anionic fraction are shown in Fig. 2. The mean total ionic mass fractions for the dry, transition and wet periods were $11.4 \%, 18.2 \%$ and $16.2 \%$ respectively of the fine particle mass and $8.8 \%, 7.8 \%$ and $6.9 \%$ of the coarse particle mass (Fig. 3). The anionic fraction of fine smoke particles consists mostly of sulfate (average about 60\%) followed by $\mathrm{C}_{2}-\mathrm{C}_{6}$ DCA (average about $22.5 \%$, with oxalate accounting for about half of it). The nitrate average relative abundance was only about $6 \%$. The average relative abundance of nitrate was not substantially greater than that of the aromatic acids and monocarboxylic acids (MCA), while the average relative abundance of tricarboxylic acids (TCA) reached about $1 \%$. The cationic fraction is dominated by ammonium $(>60 \%)$ and $\mathrm{K}^{+}$(>30\%; not shown). The $\mathrm{K}^{+}$to $\mathrm{NH}_{4}^{+}$mass ratio in the fine size fraction decreased from $0.7 \pm 0.2$ in the dry period to $0.25 \pm 0.05$ in the wet period (Fig. 4), presumably reflecting the decrease in fresh biomass burning emissions, and mixing with different aerosol types. It is noted, though, that realtime inorganic composition measurements differed somewhat from the filter results (Trebs et al., 2004). An intercomparison of different samplers' performances and results will be discussed in a subsequent paper.

Interestingly, while the total ionic mass fraction in the dry, transition and wet periods did not differ much, the composition of both anionic and cationic fractions was substantially different in the wet period (Table 3; Figs. 2 and 3). In wet

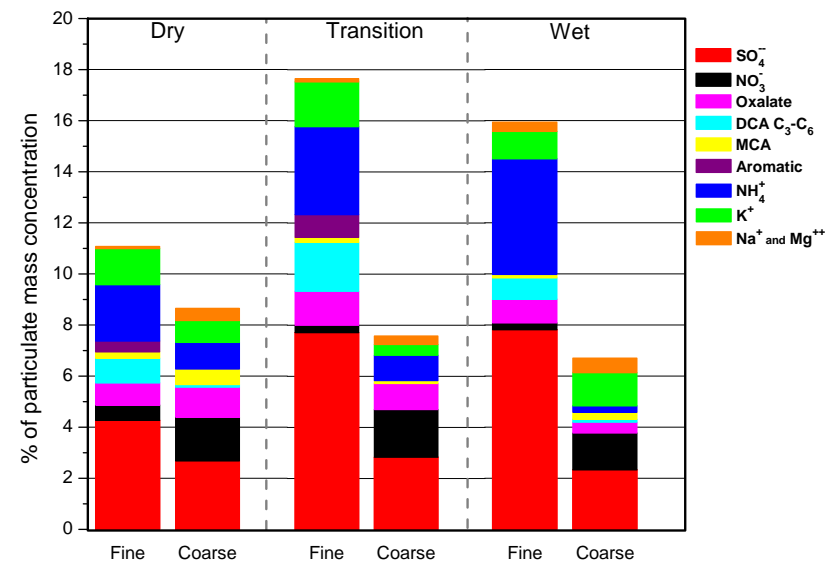

Fig. 3. Ionic mass fraction ${ }^{\mathrm{a}}$ in the fine and coarse size fractions of SFU samples collected at FNS, Rondônia, September-November, 2002. For ion concentration range refer to Table 3.

${ }^{a}$ For presentation purposes, MSA and TCA accounting together for about $0.25 \%$ of FPM in the dry and transition periods and $\mathrm{Cl}^{-}$ accounting for about $0.2 \%$ of particulate mass in each fraction for each period are not shown.

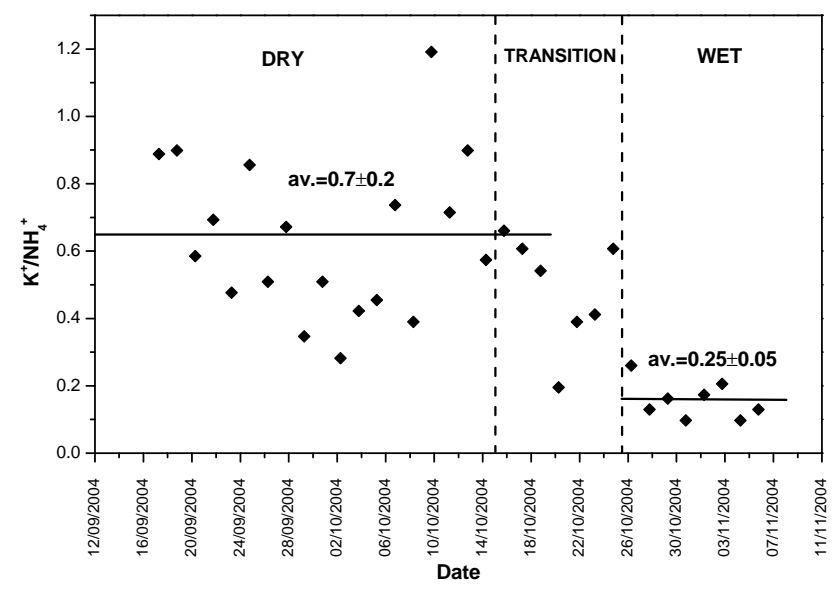

Fig. 4. Potassium-to-ammonium ratio in SFU fine size fractions.

period samples, the relative abundances of MCA and (to a lesser extent) DCA decreased, TCA and aromatic acids were absent, and sulfate and ammonium became more dominant, particularly in the fine fraction.

Ion concentrations of sulfate and potassium in the fine fraction measured by IC were compared with their elemental concentrations measured by IFUSP (Institute of Physics, University of São Paulo) by particle-induced X-ray emission (PIXE) for the same samples, for data quality assurance. Figure 5 shows a very good correlation between the cation and anion chromatography results and the PIXE data, corroborating the ion chromatography results.

Dicarboxylic $\mathrm{C}_{2}-\mathrm{C}_{6}$ acids made up $2.0 \%$ ( $\mathrm{SD}=1.1 \%$; maximum $=3.7 \%$ ) and one-ring aromatic acids made up $0.8 \%$ 

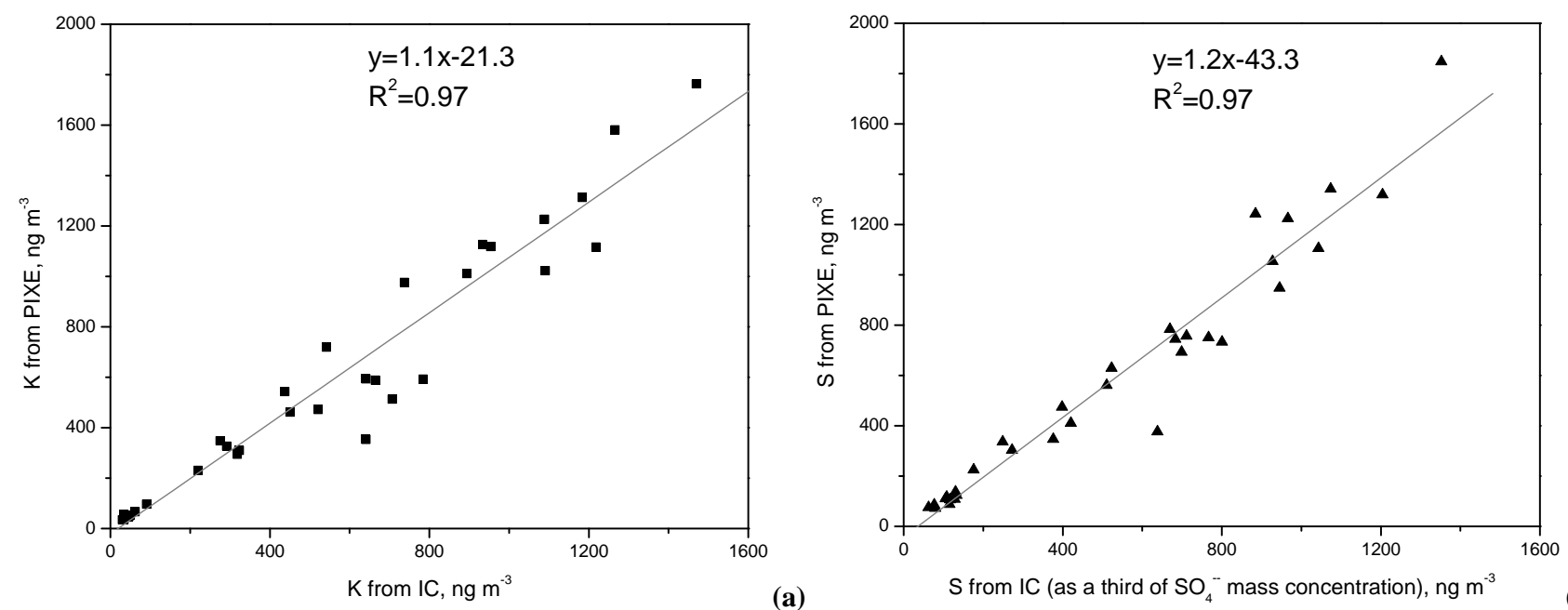

Fig. 5. Comparison between Potassium (a) and Sulfur (b) mass concentrations measured by PIXE and by ion chromatography in samples collected in FNS, Rondônia, Brazil, 2002.

Table 4. Selected size resolved ion mass concentrations identified by IC in aqueous extracts of MOUDI aerosol samples from FNS, Rondônia, Brazil, September-November, 2002.

\begin{tabular}{|c|c|c|c|c|c|c|c|c|c|c|c|}
\hline & & & Ion ma & ncentrati & 1ormaliz & the size $b$ & $\mathrm{ng} \mathrm{m}^{-3}(\mathrm{~d}$ & $/ d \log D$ & & & \\
\hline & $\begin{array}{l}\text { Cut off, } \\
\mu \mathrm{m}\end{array}$ & $\mathrm{ng} \mathrm{m}^{-3}$ & $\mathrm{NO}_{3}{ }^{-}$ & $\mathrm{SO}_{4}{ }^{2-}$ & MCA & Oxalic & Malonic & $\begin{array}{l}\text { DCA } \\
\mathrm{C}_{4}-\mathrm{C}_{6}\end{array}$ & $\begin{array}{l}\text { Aro- } \\
\text { matic }\end{array}$ & $\mathbf{N H}_{4}{ }^{+}$ & $\mathbf{K}^{+}$ \\
\hline & $<0.093$ & 1265.7 & 0.4 & 43.5 & 4.6 & 6.2 & 0.0 & 6.3 & 0.0 & 20.0 & 7.4 \\
\hline & 0.093 & 24321.6 & 27.7 & 910.9 & 148.5 & 194.7 & 0.0 & 176.2 & 0.0 & 436.1 & 247.3 \\
\hline & 0.175 & 67917.1 & 376.3 & 2262.7 & 462.3 & 793.3 & 128.5 & 519.6 & 293.8 & 1111.8 & 808.2 \\
\hline & 0.33 & 149221.2 & 1869.6 & 6998.6 & 1832.5 & 937.9 & 476.5 & 1426.0 & 842.4 & 2657.4 & 1806.6 \\
\hline 产 & 0.56 & 75356.6 & 887.2 & 3624.9 & 910.7 & 1260.1 & 235.2 & 700.8 & 1134.3 & 1163.6 & 775.8 \\
\hline 홍 & 1 & 39116.0 & 444.5 & 1542.7 & 447.8 & 629.1 & 89.7 & 346.9 & 0.0 & 378.8 & 350.6 \\
\hline$\tilde{n}$ & 1.8 & 14044.7 & 280.5 & 247.6 & 59.2 & 197.8 & 13.7 & 15.9 & 0.0 & 0.0 & 25.1 \\
\hline 䒕 & 3.2 & 19403.2 & 545.5 & 147.5 & 55.9 & 123.7 & 16.6 & 14.3 & 0.0 & 9.7 & 42.9 \\
\hline & 10 & 7150.2 & 122.0 & 33.9 & 67.8 & 15.8 & 0.0 & 0.0 & 0.0 & 0.0 & 0.0 \\
\hline & $<0.093$ & 565.9 & 0.5 & 13.8 & 3.2 & 2.6 & 0.0 & 0.9 & 0.0 & 4.5 & 3.9 \\
\hline & 0.093 & 11298.1 & 18.2 & 251.4 & 62.2 & 48.9 & 0.0 & 15.9 & 0.0 & 83.9 & 118.6 \\
\hline & 0.175 & 19993.5 & 85.3 & 386.5 & 150.2 & 192.8 & 17.1 & 74.3 & 36.8 & 167.9 & 190.2 \\
\hline ह & 0.33 & 22951.1 & 168.7 & 1005.4 & 190.2 & 247.8 & 31.3 & 176.9 & 62.2 & 348.0 & 295.5 \\
\hline 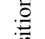 & 0.56 & 8982.5 & 25.2 & 359.8 & 60.5 & 124.7 & 11.0 & 31.9 & 56.4 & 130.5 & 100.0 \\
\hline 胥 & 1 & 5609.7 & 60.6 & 173.9 & 67.4 & 75.3 & 3.4 & 11.5 & 0.0 & 24.0 & 30.8 \\
\hline$n$ & 1.8 & 4753.4 & 128.7 & 47.3 & 8.4 & 35.6 & 0.0 & 0.0 & 0.0 & 0.0 & 19.3 \\
\hline 䒕 & 3.2 & 9812.4 & 191.8 & 33.0 & 27.4 & 27.8 & 1.6 & 14.3 & 0.0 & 8.3 & 69.5 \\
\hline & 10 & 3100.1 & 32.2 & 22.5 & 16.0 & 4.3 & 0.0 & 0.0 & 0.0 & 2.2 & 7.7 \\
\hline & $<0.093$ & 177.5 & 0.1 & 7.8 & 0.2 & 0.6 & 0.0 & 0.2 & 0.0 & 2.4 & 1.3 \\
\hline & 0.093 & 1359.9 & 4.9 & 86.5 & 3.8 & 4.7 & 0.0 & 1.7 & 0.0 & 22.5 & 12.0 \\
\hline & 0.175 & 2851.6 & 4.5 & 240.2 & 5.1 & 7.7 & 1.6 & 19.7 & 0.0 & 84.9 & 28.5 \\
\hline & 0.33 & 2927.1 & 7.1 & 303.9 & 5.7 & 9.7 & 1.2 & 17.8 & 0.0 & 100.2 & 32.3 \\
\hline 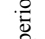 & 0.56 & 1703.4 & 5.5 & 150.3 & 1.7 & 8.5 & 0.0 & 4.1 & 0.0 & 44.0 & 16.0 \\
\hline $\begin{array}{l}\overline{0} \\
3\end{array}$ & 1 & 1527.0 & 17.8 & 43.8 & 3.8 & 12.1 & 0.0 & 2.2 & 0.0 & 10.4 & 8.2 \\
\hline 8 & 1.8 & 3402.7 & 48.0 & 29.3 & 5.2 & 13.4 & 0.0 & 5.4 & 0.0 & 6.1 & 19.8 \\
\hline है & 3.2 & 1514.9 & 66.5 & 21.4 & 13.2 & 10.8 & 0.0 & 11.0 & 0.0 & 3.0 & 45.1 \\
\hline$\Sigma$ & 10 & 1710.2 & 14.1 & 8.1 & 3.7 & 3.1 & 0.0 & 0.0 & 0.0 & 0.6 & 4.1 \\
\hline
\end{tabular}


( $\mathrm{SD}=0.6 \%$; maximum $=2 \%$ ) of the fine fraction WSOC measured in the dry period (WSOC data obtained from parallel HiVol samples was provided by Ghent University).

\subsection{MOUDI data}

The MOUDI measurements presented here provide for the first time, to the best of our knowledge, detailed information about the distribution of different organic ions in smoke particles from Brazil as a function of the particles' aerodynamic size, following the transition from dry to wet periods. Mass concentration data for one set of MOUDI samples typical for each period is presented in Table 4 to exemplify the concentration ranges in the different periods. Concentrations are normalized to the size bin of each impactor stage $(\mathrm{dC} / \mathrm{d} \log$ $\mathrm{D}_{p}$ ), where $\mathrm{C}$ is the mass concentration of a compound in a specific size bin and $\mathrm{Dp}$ is particle aerodynamic diameter (Seinfeld and Pandis, 1997). Figure 6 shows normalized mass distributions of characterized ionic species in selected MOUDI samples, as well as mass loading (PM) as a function of size. To enable comparison between size distributions of ions with significantly different mass loadings, Fig. $6 \mathrm{a}-\mathrm{f}$ presents normalized mass distributions of the different components $\mathrm{dC} /\left(\mathrm{C}_{\text {total }} \mathrm{d} \log \mathrm{D}_{p}\right)$, where $\mathrm{C}_{\text {total }}=\Sigma \mathrm{C}_{i}$ and $\mathrm{C}_{i}$ is the mass concentration of the specific species in the $i^{\prime}$ th bin. For discussion purposes, particles with aerodynamic diameter smaller than $1.8 \mu \mathrm{m}$ are classified as fine particles, and particles larger than $3.2 \mu \mathrm{m}$ as coarse particles. In general, particles with aerodynamic diameter ranging between 1.8 and $3.2 \mu \mathrm{m}$ have a small contribution to the total particulate mass.

The following aspects of the ion size distributions are noted:

1. In agreement with the SFU data, the highest mass concentrations of all ions in the fine mode were observed during the dry period, when biomass burning was most intense (Table 4).

2. Size distributions of PM and ionic species collected during the dry period are very similar to each other, especially those in MDRO37 and MDRO39 (Fig. 6a, b). Most of the particulate mass was concentrated between 0.2-1 $\mu \mathrm{m}$. The size distributions of $\mathrm{NH}_{4}^{+}, \mathrm{K}^{+}, \mathrm{SO}_{4}^{2-}$ and all organic anions, MCA, DCA and one-ring aromatic acids, also peaked in this size range. A very minor amount of oxalate was found in particles larger than $1.8 \mu \mathrm{m}$. Only $\mathrm{NO}_{3}^{-}$exhibited a bimodal size distribution with substantial mass fraction in the coarse mode.

The size distributions of species in MDRO40 sample (Fig. 6c) exhibited, in general, features similar to those of MDRO37 and MDRO39, but the distribution maximum was slightly skewed towards the higher size bins. PM exhibited some increase in the coarse mode as well. It was the only sample where a high concentration of $\mathrm{Na}^{+}$and $\mathrm{Cl}^{-}$was found in the coarse mode (not shown).
During sampling a $20 \mathrm{~mm}$ rain event occurred, an unusual event for the dry season in Amazonia. $\mathrm{The}^{-}$ molar concentration in a rainwater sample collected on the same day, and analyzed by the IFUSP group, was equal to that of $\mathrm{Na}^{+}$, indicating the presence of $\mathrm{NaCl}$ in the rainwater. The $\mathrm{Cl}^{-}$concentration in the rainwater sample $(200 \mu \mathrm{g} / \mathrm{L})$ was almost as high as the $\mathrm{SO}_{4}^{2-}$ concentration $(230 \mu \mathrm{g} / \mathrm{L})$ (Domingues and Artaxo, unpublished results).

3. Size distributions of ionic species measured during the transition period (Fig. 6d, e) exhibited in general features similar to those observed in the dry period, but some $\mathrm{K}^{+}$and organic acids were found also in the coarse mode. The PM distribution is similar to that obtained for the MDRO40 sample; however, very low $\mathrm{Na}^{+}$ and $\mathrm{Cl}^{-}$concentrations were observed in the transition period samples. $\mathrm{NO}_{3}^{-}$was mostly found in the coarse mode.

4. In the wet period sample, the particulate mass loading was distributed almost equally between all impactor stages (Fig. 6f). The fine mode continued to dominate only for ammonium and sulfate, while carboxylic acid distributions shifted to higher size bins. No aromatic acids were found in the wet period. Both $\mathrm{K}^{+}$and $\mathrm{NO}_{3}^{-}$peaked in the coarse mode. Phosphate was found only in the wet period MOUDI sample and it was only present in the coarse mode.

In Fig. 7 ionic mass concentrations as a percent of PM (hereafter referred to as ionic mass fraction) vs. particle size for a single sample from each of the dry and wet periods are presented. The ionic mass fractions in the dry, transition and wet periods account for about the same $15-16 \%$ of the PM $\left(\mathrm{Cl}^{-}\right.$and TCA are not shown). However, the organic fraction in the fine mode size bins is substantially higher for dry period samples than the wet period sample (about $40 \%$ vs. $10 \%$ ), with $\mathrm{C}_{2}-\mathrm{C}_{6}$ dicarboxylic acids making up the major part of the organic ionic mass fraction in the fine mode. In the dry period, the total ionic mass fraction has a peak in the $0.56-1.0 \mu \mathrm{m}$ range, while in the wet period, the maximum shifts to a smaller size range, $0.33-0.56 \mu \mathrm{m}$. Aromatic acids are confined only to the size bin with the highest ionic mass fraction, i.e. $0.56-1.0 \mu \mathrm{m}$, and are absent from the wet period sample.

\subsection{High Volume sampler (HiVol) data}

Ion mass concentrations in the front and back filters of the fine samples collected by the HiVol sampler during the dry and transition periods were determined. When performing an intralaboratory comparison between the SFU (polycarbonate membrane) and HiVol (quartz fiber filter) samples, it was observed that some species (such as sulfate) correlated very well between the two sample sets, while other 
A. H. Falkovich et al.: Low molecular weight organic acids in smoke aerosol
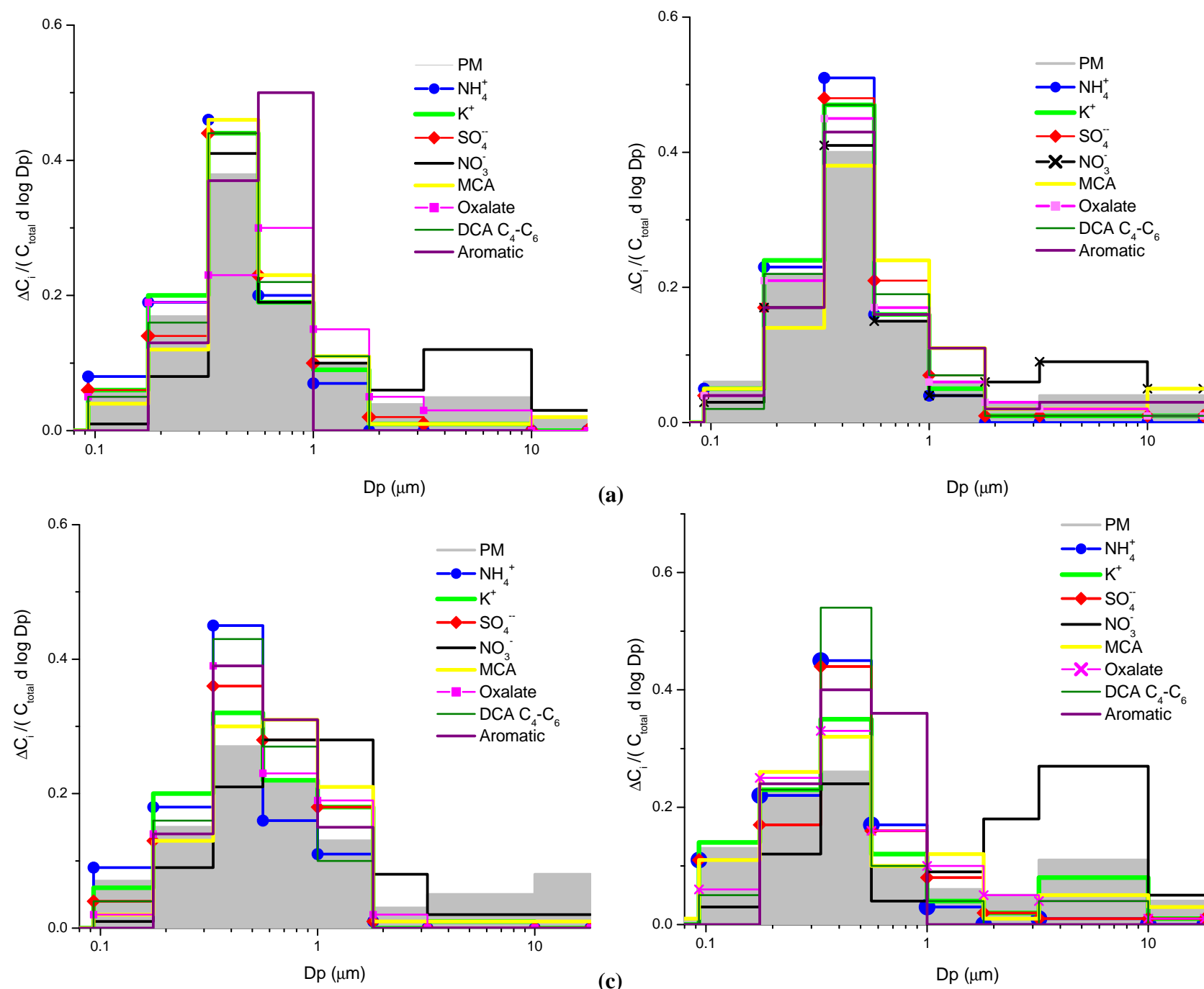

(a)

$\mathrm{Dp}(\mu \mathrm{m})$

(b)
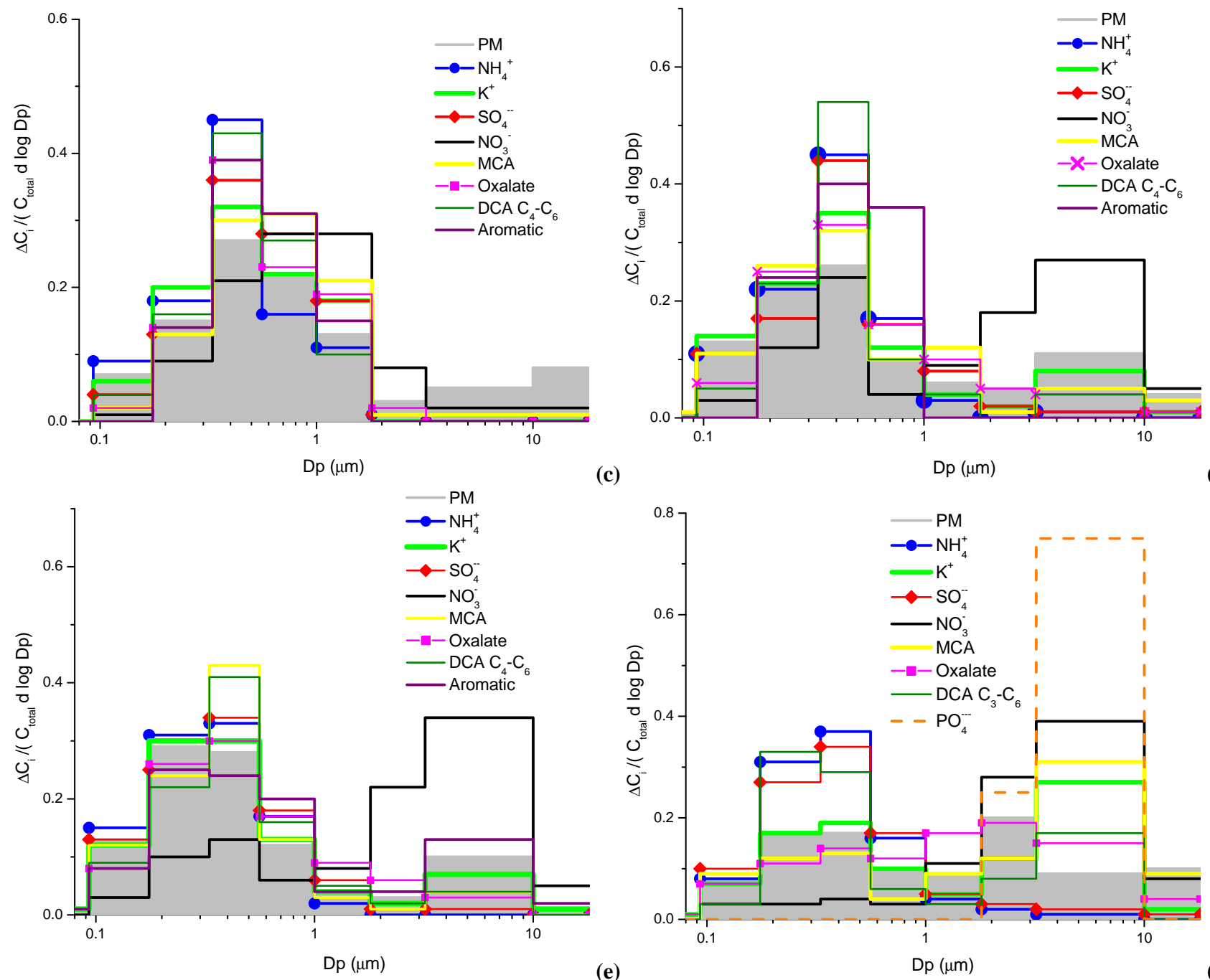

(d)

Fig. 6. Normalized size concentrations of ionic species as a function of the particle aerodynamic diameter in MOUDI samples collected in FNS, Rondônia, Brazil, 2002: (a) MDRO37; (b) MDRO39; (c) MDRO40; (d) MDRO53; (e) MDRO54; (f) MDRO60b. 
Table 5. Back-to-front filter ratio (\%) determined by IC for aqueous extracts of HiVol aerosol samples from FNS, Brazil, 2002 (estimates the positive artifact due to adsorption of gaseous compounds by filters).

\begin{tabular}{lcccccccc}
\hline & $\begin{array}{c}\text { Glycolic+Glyceric+ } \\
\text { Acetic+Lactic }\end{array}$ & Formic & NO $_{3}^{-}$ & DCA C3-C6 & SO4 $^{2-}$ & Oxalate $^{\text {N }}$ & NH $_{4}^{+}$ & $\mathbf{K}$ \\
\hline median & 29.10 & 23.55 & 7.97 & 4.54 & 5.07 & 7.40 & 1.28 & 1.20 \\
mean & 33.44 & 26.23 & 10.07 & 5.41 & 6.08 & 6.90 & 1.91 & 1.63 \\
minimum & 6.19 & 8.77 & 1.46 & 1.20 & 3.15 & 0.84 & 0.00 & 0.00 \\
maximum & 84.32 & 79.57 & 31.15 & 13.91 & 17.19 & 16.68 & 4.72 & 7.74 \\
standard deviation & 21.42 & 15.60 & 8.30 & 3.94 & 3.18 & 4.88 & 1.36 & 1.55 \\
\hline
\end{tabular}

a Due to problematic separation, peaks are integrated as a group peak.

species, such as nitrate and oxalate, had concentrations about twice as high in HiVol samples as compared with SFU samples. It is known that quartz fiber filters have a large specific area on which adsorption of gases can occur (Turpin et al., 2000). In addition, it is possible that the quartz fiber filter may be wetted at high relative humidities. Therefore, it is suggested that gas adsorption or oxidation processes occurring on the quartz fiber filters might have resulted in positive artifacts during HiVol sampling. Consequently, we used the data obtained from the HiVol samples only for resolving issues which could not be fully addressed based on SFU samples. On the other hand, it should be noted that negative artifacts (volatilization losses) may have existed for the SFU and MOUDI samples, in particular in the fine size fractions, because of the relative low pressure conditions during sampling.

To estimate the positive artifact caused by adsorption of gaseous compounds by quartz fiber filters (Novakov et al., 1997; Turpin et al., 2000), ratios of the ionic mass concentration on the back filter sample to that on the front filter sample were calculated for selected ions (Table 5). Among the organic acids, only MCA and MSA were present in substantial amounts on the back filters (16-30\% of the front filter concentrations). Therefore, it appears that they have been significantly adsorbed from the gas phase, while DCA and aromatic acid adsorption is comparable to that of a non-volatile compound such as sulfate.

\section{Discussion}

Evidently, the composition of the Amazonian aerosols analyzed in this work was heavily impacted by vegetation combustion. However, since chemical composition evolves during aerosol aging, and combustion is not the only aerosol source in the region, it is challenging to evaluate the actual proportion of primary combustion products in the determined aerosol chemical composition. Fine size fraction $\mathrm{K}^{+}$is a highly useful tracer for pyrogenic aerosols, since combustion of plant material releases large amounts of $\mathrm{K}^{+}$-rich particles in the submicrometer size mode (Andreae, 1983). The near
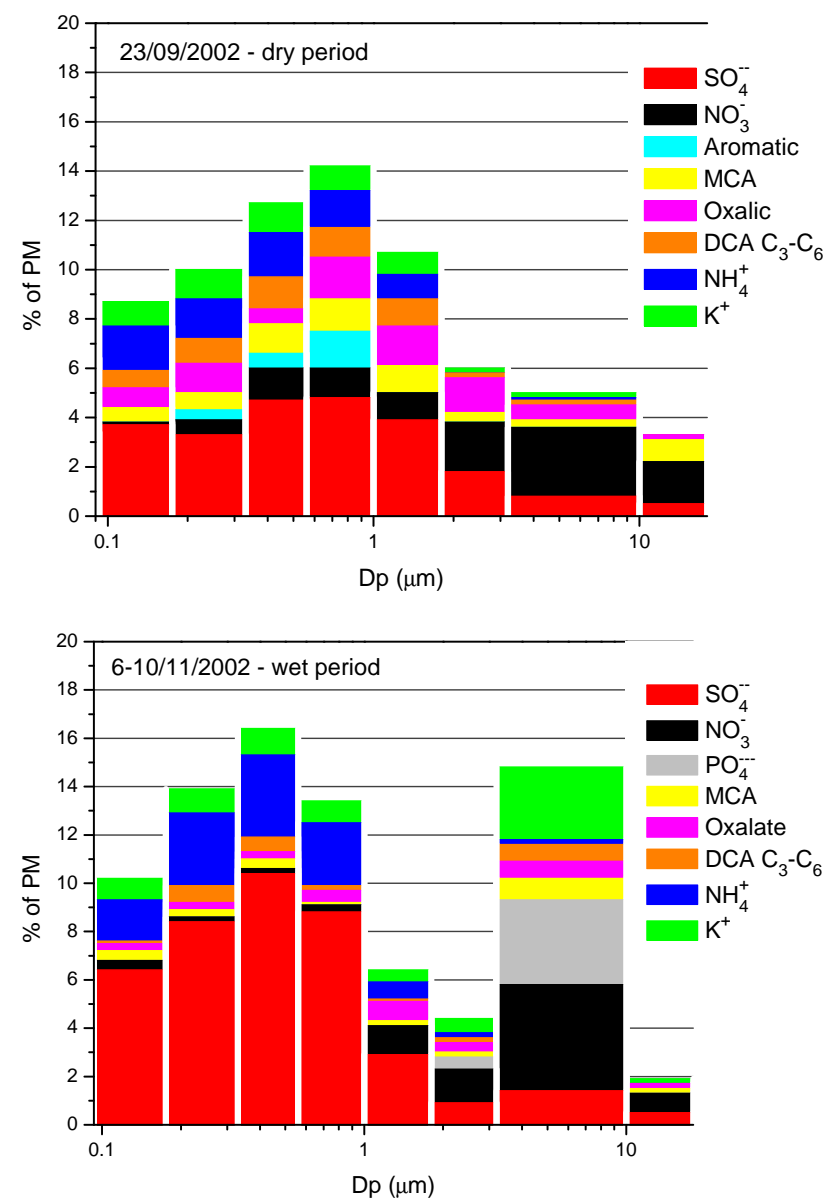

Fig. 7. Ionic mass fraction as a function of the particle aerodynamic diameter in MOUDI samples collected in FNS, Rondônia, Brazil, 2002: (a) MDRO37; (b) MDRO60b.

unity slope in comparison with elemental analysis by PIXE (Fig. 5) indicates that almost all fine mode $\mathrm{K}$ in the particles is present in water-soluble (cationic) form. Therefore, we consider fine size fraction species whose temporal profile correlates well with that of $\mathrm{K}^{+}$, as species which are produced by vegetation combustion. We used this approach to 


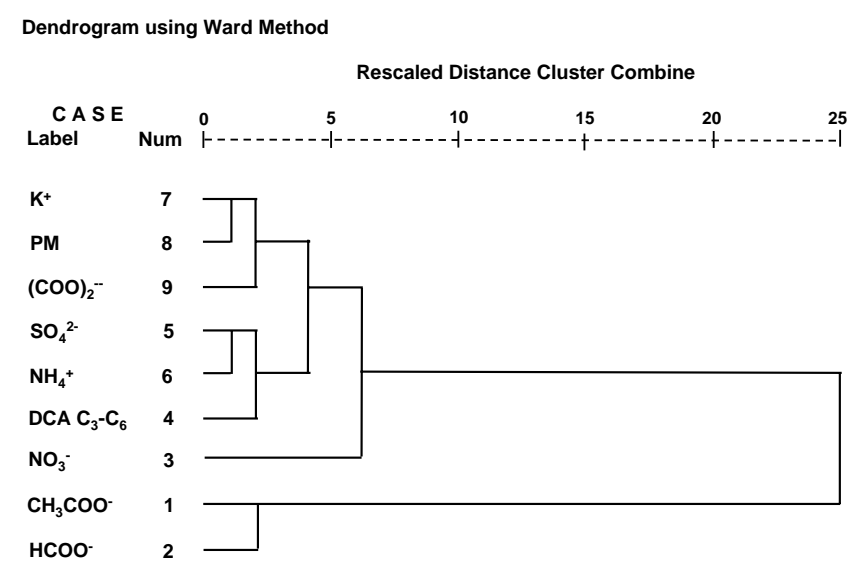

Fig. 8. Dendrogram of the cluster analysis showing the grouping of species determined in the fine fraction with similar characteristic for dry and transition periods.

investigate the origin of the low molecular weight organic acids. FPM and the mass concentrations of $\mathrm{NH}_{4}^{+}, \mathrm{NO}_{3}^{-}$, $\mathrm{SO}_{4}^{2-}$, DCA and aromatic acids measured in the SFU samples (shown in Fig. 1) followed the same temporal trends as $\mathrm{K}^{+}$, suggesting that the fine aerosol, in general, and these ionic species, in particular, were produced mostly by vegetation combustion.

4.1 Relationships between ionic species measured in SFU samples - cluster analysis

Cluster analysis was used to obtain statistically meaningful correlations between the major ionic species in the fine size fraction and to corroborate the conclusions derived based on the chemical analysis and the size distributions. Details of the procedure are described by Artaxo et al. (1990).

Results from cluster analysis of dry and transition period samples are shown graphically in Fig. 8 in the form of a dendrogram. $\mathrm{K}^{+}$highly correlates with FPM, indicating that the fine aerosols consist mainly of smoke particles, as was further supported by the size distributions and by temporal behavior of levoglucosan, a specific biomass burning tracer, in a related paper (Schkolnik et al., 2005). The close association of oxalate to this cluster suggests that its dominating source is vegetation combustion and not secondary photochemical processes. Sulfate and $\mathrm{NH}_{4}^{+}$, comprising non-volatile ammonium sulfate by gas to particle conversion, compose a separate cluster. The calculated molar ammonium to sulfate ratio obtained by IC analysis was greater than 2 , suggesting that sulfate is completely neutralized by ammonia to form $\left(\mathrm{NH}_{4}\right)_{2} \mathrm{SO}_{4}$ salt.

The recently published size-resolved measurements reporting episodes of elevated LMW DCA concentrations due to biomass burning plumes passing over the measurement site (Jaffrezo et al., 1998; Ma et al., 2003), have found that the size distributions of $\mathrm{K}$ and DCA were skewed toward the accumulation mode and exhibited the very same shape as sulfate's, suggesting internal mixing of these species in the same particles. Thus, considering the proximity of the DCA C3-C6 cluster to the ammonium sulfate cluster (Fig. 8), the similarity of their size distribution to that of $\mathrm{SO}_{4}^{2-}$ and $\mathrm{NH}_{4}^{+}$(Fig. 6a, b) and their proximity to the $\mathrm{PM}$ and $\mathrm{K}^{+}$ cluster, we suggest that they have a strong common vegetation combustion source, and that they may form ammonium salts, which may play an important role in determining the thermodynamic properties of the aerosol (Trebs et al., 2005). Acetic and formic acids appear in the furthest class, suggesting that they either have a different source in the particles, or behave differently from the other species considered here, due to their higher vapor pressure.

\subsection{Size distributions of the ionic species}

Analysis of the MOUDI samples shows that during the dry period, most of the particulate mass was concentrated in sizes smaller than $1.8 \mu \mathrm{m}$ (Fig. 6a-c), peaking in mass at $0.2-$ $1 \mu \mathrm{m}$, indicating the dominant size range of the smoke particles. In the dry period (Fig. 6a-c), PM and most of the ion size distributions exhibit a maximum between $0.33-0.56 \mu \mathrm{m}$. In a related paper, Decesari et al. $(2005 b)^{4}$ show that in this size-bin, all species show a peak. Considering this, the peak of the total ionic mass to PM ratio between $0.56-1.0 \mu \mathrm{m}$ in Fig. $7 \mathrm{a}$, indicates that species which were not analyzed in this work, constitute a larger fraction in the $0.33-0.56 \mu \mathrm{m}$ size-bin during the dry season.

$\mathrm{C}_{2}-\mathrm{C}_{6}$ DCA were mostly found in submicrometer particles and appear in the same cluster as $\left(\mathrm{NH}_{4}\right)_{2} \mathrm{SO}_{4}$, closest to FPM and $\mathrm{K}^{+}$cluster (Fig. 8). Thus we infer that they have a common source. However, a relatively high abundance of oxalate was observed also in the coarse anionic fraction (Fig. 3 and Table 3), pointing to an additional potential DCA source. A field study in the Southern African savanna (Formenti et al., 2003) suggested a possible distribution pattern of oxalate during aerosol transport, whereby certain gas-phase smoke components are converted by atmospheric oxidants to DCA through sequential decarboxylation and oxidation. Therefore, DCA may have at least two sources: primary production during biomass burning and secondary production during aerosol transport.

Consistent with the conclusions from the SFU, the molar ammonium to sulfate ratio in the MOUDI samples was close to or greater than 2 in the $0.093-1.0 \mu \mathrm{m}$ size range, indicating that all $\mathrm{SO}_{4}^{2-}$ was neutralized to $\left(\mathrm{NH}_{4}\right)_{2} \mathrm{SO}_{4}$, which is the dominant salt in these aerosols. The size distributions of the aromatic and aliphatic carboxylic acids are similar to that of $\mathrm{K}^{+}$, suggesting that they were predominantly emitted with smoke aerosol.

Nitrate has a bimodal size distribution, with a contribution from the coarse mode, consistent with the SFU samples and the cluster analysis (Table 3, Fig. 8), suggesting that a process other than direct emission is responsible for 
nitrate in the coarse mode. Recent studies on nitrate in biomass burning plumes suggested that $\mathrm{NO}_{\mathrm{x}}$ emitted from the fires forms nitric acid by reactions with atmospheric oxidants such as $\mathrm{O}_{3}$ or $\mathrm{OH}$. (Gao et al., 2003), which condenses onto alkaline particles such as mineral dust or biomass burning aerosol (Tabazadeh et al., 1998; Song and Carmichael, 2001). Therefore, nitrate is a secondary product in biomass burning aerosols replacing organic and inorganic anions with $\mathrm{HNO}_{3}$ (Tabazadeh et al., 1998; Trebs et al., 2005), or through neutralization of nitric acid by ammonium to form ammonium nitrate $\left(\mathrm{NH}_{4} \mathrm{NO}_{3}\right)$ (Seinfeld and Pandis, 1997).

An increase in $\mathrm{PM}$ and high $\mathrm{Na}^{+}$and $\mathrm{Cl}^{-}$concentrations observed in the coarse mode of sample MDRO40, coincided with a short rain event. The equal $\mathrm{Na}^{+}$and $\mathrm{Cl}^{-}$molar concentration in a rainwater sample collected on the same day may indicate the presence of aged sea salt in the rainwater. However, penetration of marine air masses to the sampling area seems improbable. Even if air masses from the Atlantic reached the Rondônia region, most of the marine aerosols would be wet-deposited during the several days of transport. We currently do not have a good explanation for the presence of $\mathrm{NaCl}$ in these samples.

In the wet period MOUDI samples, PM is distributed almost equally among all impactor stages. Carboxylic acids as well as $\mathrm{K}^{+}$appear also in the higher size bins. This observation reflects a relative dearth of fresh smoke emissions, and implies the existence of other sources, not from biomass burning, for these species. This is consistent with the absence of levoglucosan, a specific biomass burning tracer, from the coarse mode in all periods (Schkolnik et al., 2005). A possible source for such carboxylic acids may be biogenic emissions (Guyon et al., 2004; Kocak et al., 2004). This is further substantiated by the presence of phosphate (known to be a biogenic emission marker) which was observed exclusively in the wet period MOUDI sample and only in the coarse mode. The contribution from other aerosol sources agrees also with the crustal enrichment factor for $\mathrm{K}$ in the coarse modes in the wet period which was typically around 3 with respect to Mason's average crustal rock composition (Mason and Moore, 1982), using Al as crustal reference element. This indicates that an additional aerosol source may be mineral dust, plant debris, plant spores or bacteria. The high DCA concentrations in the coarse mode could be also partly attributed to photochemical processes followed by condensation (Chebbi and Carlier, 1996). It was also suggested that oxalic and malonic acids can be produced by degradation of higher DCA on particles (Kawamura and Ikushima, 1993). Finally, the shift of DCA and $\mathrm{K}^{+}$to higher sizes may also suggest mixing between aerosol populations by in-cloud processing followed by evaporation.
4.3 Organic acids in the tandem front/back filter system (HiVol)

The ubiquity of DCA in biomass burning particles requires that their concentrations in aerosols be accounted for correctly in models. Although carboxylic acids have been studied in the gas and particulate phases, most of the data refer to monocarboxylic acids (formic and acetic). To our knowledge, the few field studies that attempted to monitor gasparticle partitioning of dicarboxylic acids have led to contradicting conclusions about their semi-volatile behavior (Saxena and Hildemann, 1996; Baboukas et al., 2000; Limbeck et al., 2001; Mochida et al., 2003). Specifically, recent field studies reported that low molecular weight DCA are semivolatile (Baboukas et al., 2000; Limbeck et al., 2001), while other studies concluded that they are mostly confined to the particulate phase (Saxena and Hildemann, 1996; Mochida et al., 2003). Limbeck's conclusions about semi-volatile behavior of the $\mathrm{C}_{2}-\mathrm{C}_{6}$ DCA were based on the presence of significant concentrations of DCA on the back filter (Limbeck et al., 2001). In contrast, $C_{2}-C_{6}$ DCA concentration ratios of back to front filters in our samples did not exceed $0.071 \pm 0.066$. A similar ratio $(0.059 \pm 0.034)$ was obtained for the non-volatile sulfate.

The sampling set-up applied in the present study does not differ substantially from that used by Limbeck et al. (2001), where samples were collected using an open-faced lowvolume sampler equipped with a front/back filter tandem system of quartz fiber filters. A major difference is that in the Limbeck et al study, sampling intervals were about a week, and collected samples were stored in a refrigerator $\left(0-4^{\circ} \mathrm{C}\right)$ until analysis (Limbeck et al., 2001). In the current study, the sampling intervals were shorter (about $12 \mathrm{~h}$ ) except for five transition period samples, which were collected for 24-36 h. Loaded filters were immediately placed in a freezer $\left(-25^{\circ} \mathrm{C}\right)$ and thus stored until analysis. Another plausible explanation for the different conclusions is that the prolonged sampling on quartz fiber filters leads to production of oxalic and succinic acids on the back filters. Oxalic and succinic acids can form by oxidation of high molecular weight organics, such as aromatic compounds or unsaturated fatty acids, while malonic acid cannot be produced by this pathway (Kawamura et al., 1996; Gao et al., 2003). In the study of Limbeck et al. (2001), malonic acid was confined mostly to the front filter, while oxalic and succinic acids were found also in back filters. Additional possible differences between the two studies can arise from different particles' acidity. Rondônia particles are neutral or slightly basic.

We have not found evidence for semi-volatility of DCA, and conclude that they are confined to the aerosol phase in this case. This may arise from the neutral or slightly alkaline character of the particles and from the high humidity during the field campaign, contrary to sampling conditions and aerosol $\mathrm{pH}$ reported where semi-volatility of LMW DCA was observed (Limbeck et al., 2001, 2005). A mechanism of 
Table 6. Recent studies of low molecular weight DCA in biomass burning aerosols.

\begin{tabular}{|c|c|c|c|c|c|}
\hline Region & $\begin{array}{l}\text { DCA } \\
\text { identified }\end{array}$ & $\begin{array}{l}\text { Analytical } \\
\text { method }\end{array}$ & $\begin{array}{l}\text { Oxalic } \\
\mu \mathrm{g} \mathrm{m}^{-3}\end{array}$ & $\begin{array}{l}\text { Sum of all DCA } \\
\mu \mathrm{g} \mathrm{m}^{-3}\end{array}$ & References \\
\hline Amazon basin, 2002 & $\begin{array}{l}\mathrm{C}_{2}-\mathrm{C}_{6}, \\
\text { including branched, } \\
\text { keto- and hydroxyacids }\end{array}$ & IC & $\begin{array}{l}\text { range: } \\
0.022-1.34\end{array}$ & $0.033-2.5$ & this work \\
\hline Amazon basin, 1992 & $\mathrm{C}_{2}$ & IC & $\begin{array}{l}\text { in different } \\
\text { vegetation types: } \\
0.3-28.8\end{array}$ & & Allen and Miguel (1995) \\
\hline Central Africa, 1996 & $\mathrm{C}_{2}$ & $\mathrm{IC}$ & $0.05-1.17$ & & Ruellan et al. (1999) \\
\hline Indonesian forest, 1997 & $\mathrm{C}_{2}-\mathrm{C}_{12}$ & GC/MS & & $0.087-3.8$ & Narukawa et al. (1999) \\
\hline South African savanna, 1997 & $\mathrm{C}_{2}$ & IC & 0.18 & & Puxbaum et al. (2000) \\
\hline Arabian Sea, 1999 & $\mathrm{C}_{2}$ & GC/MS & 0.18 & & Neususs et al. (2002) \\
\hline Amazon basin, 1999 & $\begin{array}{l}\mathrm{C}_{2}-\mathrm{C}_{6}, \\
\text { including branched, } \\
\text { keto- and hydroxyacids }\end{array}$ & $\begin{array}{l}\text { oxalic-IC; } \\
\text { rest-GC/MS }\end{array}$ & range: $0.14-1.33$ & 1.47 & Graham et al. (2002) \\
\hline ACE-Asia, 2001 & $\mathrm{C}_{2}-\mathrm{C}_{5}$ & GC/MS & $0.12-0.63$ & $0.16-0.90$ & Mader et al. (2004) \\
\hline
\end{tabular}

DCA confinement to the particle phase is by formation of ammonium salts of the DCA which was observed in these particles (Trebs et al., 2005). The ammonium salts would have lower vapor pressure than the free acids. Such a reduction in the volatility of inorganic acids due to high ammonium concentrations has already been observed by Pathak et al. (2004). In addition, a laboratory study (Prenni et al., 2001) found that LMW DCA partition to the condensed phase, and that once wetted in the atmosphere, these compounds remain as a metastable solution, even when dried to less than 5\% RH. These results suggest that at high relative humidity typical for the tropical rainforest $(60-100 \%)$, DCA are expected to be confined to the aerosol phase. Using a high-volume air sampler and an annular denuder sampling system with a $\mathrm{Na}_{2} \mathrm{CO}_{3}$ coated denuder to trap gaseous organic acids and a $\mathrm{Na}_{2} \mathrm{CO}_{3}$ impregnated quartz fiber filter to collect particles, Mochida et al. (2003) also measured $\mathrm{C}_{2}$ $\mathrm{C}_{5}$ DCA gas to particle partitioning, showing that their actual fractions in particles are close to unity. Saxena and Hildemann (1996) reached similar conclusions about DCA semivolatility.

4.4 Comparison with previous studies on organic acids in aerosols from vegetation burning

Detailed composition data on the ionic fraction of biomass burning aerosols is essential for understanding the impact of smoke aerosol on atmospheric chemistry and climate. Several studies have contributed to our current knowledge of organic acids in biomass burning. Some characterization studies of dicarboxylic acids in smoke aerosols collected during field campaigns in different locations and different vegetation types have been conducted. Table 6 summarizes some published DCA composition data obtained for biomass burning aerosols in different parts of the world. In these studies,
DCA in general and oxalic acid in particular, appear to be the major identified particulate organic species, with mass concentrations up to $1-4 \mu \mathrm{g} \mathrm{m}^{-3}$. It can be seen that the composition data from a field study carried out in 1999 at the same sampling site as the present study (Graham et al., 2002) agrees with the measurements presented here. The consistency between the two datasets (see Table 6) allows us to consider them representative for the emissions produced by vegetation combustion in the Amazon region. However, the 1999 study lacks the temporal variations and the size distributions reported here.

Highly dissociated organic species may affect aerosols' hygroscopic and cloud-nucleating properties, although their carbon mass fraction in WSOC averages about 3\%. Despite the fact that organic carbon (OC) is a typical parameter directly measured to quantify the organic fraction in aerosols, organic aerosol mass is more important to the chemical and physical properties of aerosols. As opposed to non-oxygenated hydrocarbons, oxygenated organic compounds, such as organic acids, contain groups whose mass and volume are substantial. Organic acids in aerosol particles have large organic matter (OM) to OC ratios (Mochida et al., 2003) because they contain oxygen atoms in - $\mathrm{COOH}$ functional groups. The $\mathrm{OM} / \mathrm{OC}$ ratios of $\mathrm{C}_{2}-\mathrm{C}_{6} \mathrm{DCA}$ range from 3.8 (oxalic acid) to 2.0 (adipic acid), indicating that their contributions to the particle mass is larger than that calculated on the basis of carbon only. Another important role of organic acids relating to their contribution to the smoke aerosol mass is the formation of salts. Both organic acids and $\mathrm{NH}_{4}^{+}$were predominantly present in submicron size particles and the ammonium was in excess of $\mathrm{SO}_{4}^{2-}$, and nitrate. Using an updated version of the equilibrium simplified aerosol model (EQSAM), which incorporates mineral aerosol species and lumped LMW organic acids obtained in 
this study, it was shown that carboxylic acids have to be taken into account (Trebs et al., 2005) in order to balance the fine mode aerosol inorganic ionic charges. When organic acids are present as ammonium salts, their contribution to the total aerosol mass increases even more (e.g. OM/OC=5.2 for oxalic acid as $\left(\mathrm{COONH}_{4}\right)_{2}$ instead 3.8 for free oxalic acid).

\section{Conclusions}

Examining the link between aerosol chemical/physical properties and aerosol hygroscopic and cloud-nucleating properties, and modeling the effect of biomass burning aerosol on cloud microphysics at the cloud and regional level, has been one of the overall goals for the SMOCC field study. It is not a trivial task to model microphysical characteristics of smoke aerosols, due to their complex chemical composition. Such modeling requires size distribution data of aerosol chemical composition. To the best of our knowledge, this is the first study that reports size distributions of organic acids in smoke aerosols from this region.

The measurements presented in this paper provide a comprehensive dataset for the chemical composition of the water soluble fraction in biomass burning particles in Brazil, and demonstrate how chemical composition changes with the transition from the burning season to clean conditions. While the chemical composition obtained from bulk measurements shows little differences between the three periods, the size resolved data shows substantial differences in the distribution of species among the different size ranges as the aerosols age and are mixed with other aerosol types. The distributions also shed light on the different sources of species.

In this study low molecular weight polar organic acids were found to account for a significant fraction of the water soluble organic carbon (WSOC) in biomass burning aerosols $-\mathrm{C}_{2}-\mathrm{C}_{6}$ dicarboxylic acids accounted for up to $3.7 \%$ and one-ring aromatic acids accounted for up to $2 \%$ of fine fraction WSOC during burning period. These short dicarboxylic $\left(\mathrm{C}_{2}-\mathrm{C}_{6}\right)$ acids are dominated by oxalic acid, followed by malonic and succinic acids. The most abundant ionic species is ammonium sulfate, accounting for $60-70 \%$ of ionic mass. It was found that most of the ionic mass is concentrated in submicrometer-sized particles. Based on the size distribution and correlations with $\mathrm{K}^{+}$, a known biomass burning tracer, it is suggested that during the dry season many of the organic acids are directly emitted by vegetation fires. It is concluded that the dicarboxylic acids are mostly confined to the particulate phase, and no evidence for semi-volatile behavior was observed.

Acknowledgements. This work is a contribution to the Large Scale Biosphere-Atmosphere Experiment in Amazonia (LBA). We are indebted to the European Commission, Contract EVK2-CT-200100110, the Belgian Federal Science Policy Office, the "Fonds voor Wetenschappelijk Onderzoek - Vlaanderen", the FAPESP and $\mathrm{CNPq}$, Brazil, for research support, and the Henri Gutwirth
Fund for Promotion of Research at the Weizmann Institute. We thank A. C. Ribeiro, A. L. Loureiro, T. Germano, G. Nishioka and J. Cafmeyer for collecting the samples at the field site and $\mathrm{X}$. Chi (Ghent Univ., Belgium) for performing the OC and WSOC measurements. The authors wish to thank S. Decesari (CNR, Bologna, Italy) and M. Claeys (Univ. of Antwerp, Belgium) for fruitful discussions.

Edited by: U. Lohmann

\section{References}

Allen, A. G. and Miguel, A. H.: Biomass burning in the Amazon - Characterization of the ionic component of aerosols generated from flaming and smoldering rain-forest and savanna, Environ. Sci. Technol., 29(2), 486-493, 1995.

Andreae, M. O.: Soot carbon and excess fine potassium - Longrange transport of combustion-derived aerosols, Science, 220, 1148-1151, 1983.

Andreae, M. O. and Crutzen, P. J.: Atmospheric aerosols: constituent of airborne particles in atmospheric chemistry, Science, 276(5315), 1052-1058, 1997.

Andreae, M. O. and Merlet, P.: Emission of trace gases and aerosols from biomass burning, Glob. Biogeochem. Cycle, 15(4), 955966, 2001.

Andreae, M. O., Rosenfeld, D., Artaxo, P., Costa, A. A., Frank, G. P., Longo, K. M., and Silva-Dias, M. A. F.: Smoking rain clouds over the Amazon, Science, 303(5662), 1337-1342, 2004.

Artaxo, P., Maenhaut, W., Storms, H., and Vangrieken, R.: Aerosol characteristics and sources for the Amazon basin during the wet season, J. Geophys. Res. A., 95(D10), 16 971-16 985, 1990.

Baboukas, E. D., Kanakidou, M., and Mihalopoulos, N.: Carboxylic acids in gas and particulate phase above the Atlantic Ocean, J. Geophys. Res., 105(D11), 14 459-14 471, 2000.

Cachier, H., Liousse, C., Buat-Menard, P., and Gaudichet, A.: Particulate content of savanna fire emission, J. Atmos. Chem., 22, 123-148, 1995.

Charlson, R. J., Seinfeld, J. H., Nenes, A., Kulmala, M., Laaksonen, A., and Facchini, M. C.: Atmospheric science - Reshaping the theory of cloud formation, Science, 292(5524), 2025-2026, 2001.

Chebbi, A. and Carlier, P.: Carboxylic acids in the troposphere, occurrence, sources, and sinks: A review, Atmos. Environ., 30(24), 4233-4249, 1996.

Decesari, S., Facchini, M. C., Fuzzi, S., and Tagliavini, E.: Characterization of water-soluble organic compounds in atmospheric aerosol: A new approach, J. Geophys. Res., 105(D1), 14811489, 2000.

Falkovich, A. H., Schkolnik, G., Ganor, E., and Rudich, Y.: Adsorption of organic compounds pertinent to urban environments onto mineral dust particles, J. Geophys. Res., 109(D2), D02208, doi:10.1029/2003JD003919, 2004.

Formenti, P., Elbert, W., Maenhaut, W., Haywood, J., Osborne, S., and Andreae, M. O.: Inorganic and carbonaceous aerosols during the Southern African Regional Science Initiative (SAFARI 2000) experiment: Chemical characteristics, physical properties, and emission data for smoke from African biomass burning, J. Geophys. Res., 108(D13), 8488, doi:10.1029/2002JD002408, 2003. 
Gao, S., Hegg, D. A., Hobbs, P. V., Kirchstetter, T. W., Magi, B. I., and Sadilek, M.: Water-soluble organic components in aerosols associated with savanna fires in southern Africa: Identification, evolution, and distribution, J. Geophys. Res., 108(D13), 8491, doi:10.1029/2002JD002420, 2003.

Graham, B., Mayol-Bracero, O. L., Guyon, P., Roberts, G. C., Decesari, S., Facchini, M. C., Artaxo, P., Maenhaut, W., Koll, P., and Andreae, M. O.: Water-soluble organic compounds in biomass burning aerosols over Amazonia - 1. Characterization by NMR and GC-MS, J. Geophys. Res., 107(D20), 8047, doi:10.1029/2001JD000336, 2002.

Guyon, P., Graham, B., Roberts, G. C., Mayol-Bracero, O. L., Maenhaut, W., Artaxo, P., and Andreae, M. O.: Sources of optically active aerosol particles over the Amazon forest, Atmos. Environ., 38(7), 1039-1051, 2004.

Hitzenberger, R., Berner, A., Galambos, Z., Maenhaut, W., Cafmeyer, J., Schwarz, J., Miller, K., Spindler, G., Wieprecht, W., Acker, K., Hillamo, R., and Makela, T.: Intercomparison of methods to measure the mass concentration of the atmospheric aerosol during INTERCOMP2000 - influence of instrumentation and size cuts, Atmos. Environ., 38, 6567-6476, 2004.

Hoffer, A., Kiss, G., Blazso, M., and Gelencser, A.: Chemical characterization of humic-like substances (HULIS) formed from a lignin-type precursor in model cloud water, Geophys. Res. Lett., 31(6), L06115, doi:10.1029/2003GL018962, 2004.

Jaffrezo, J. L., Davidson, C. I., Kuhns, H. D., Bergin, M. H., Hillamo, R., Maenhaut, W., Kahl, J. W., and Harris, J. M.: Biomass burning signatures in the atmosphere of central Greenland, J. Geophys. Res., 103(D23), 31 067-31 078, 1998.

Kaufman, Y. J. and Fraser, R. S.: The effect of smoke particles on clouds and climate forcing, Science, 277(5332), 1636-1639, 1997.

Kaufman, Y. J., Tanre, D., and Boucher, O.: A satellite view of aerosols in the climate system, Nature, 419(6903), 215-223, 2002.

Kawamura, K. and Ikushima, K.: Seasonal changes in the distribution of dicarboxylic acids in the urban atmosphere, Environ. Sci. Technol., 27(10), 2227-2235, 1993.

Kawamura, K., Semere, R., Imai, Y., Fujii, Y., and Hayashi, M.: Water soluble dicarboxylic acids and related compounds in Antarctic aerosols, J. Geophys. Res., 101(D13), 18 721-18 728, 1996.

Kirkman, G. A., Gut, A., Ammann, C., Gatti, L. V., Cordova, A. M., Moura, M. A. L., Andreae, M. O., and Meixner, F. X.: Surface exchange of nitric oxide, nitrogen dioxide, and ozone at a cattle pasture in Rondonia, Brazil, J. Geophys. Res., 107(D20), 8083, doi:10.1029/2001JD000523, 2002.

Kocak, M., Kubilay, N., and Mihalopoulos, N.: Ionic composition of lower tropospheric aerosols at a Northeastern Mediterranean site: implications regarding sources and long-range transport, Atmos. Environ., 38(14), 2067-2077, 2004.

Laaksonen, A., Korhonen, P., Kulmala, M., and Charlson, R. J.: Modification of the Kohler equation to include soluble trace gases and slightly soluble substances, J. Atmos. Sci., 55, 853862,1998

Limbeck, A., Kraxner, Y., and Puxbaum, H.: Gas to particles distribution of low molecular weight dicarboxylic acids at two different sites in central Europe (Austria), J. Aerosol Sci., in press, 2005.
Limbeck, A., Puxbaum, H., Otter, L., and Scholes, M. C.: Semivolatile behavior of dicarboxylic acids and other polar organic species at a rural background site (Nylsvley, RSA), Atmos. Environ., 35(10), 1853-1862, 2001.

Ma, J., Tang, J., Li, S., and Jacobson, M. Z.: Size distributions of ionic aerosols measured at Waliguan Observatory: Implication for nitrate gas-to-particle transfer processes in the free troposphere, J. Geophys. Res., 108(D17), 4541, doi:4510.1029/2002JD003356, 2003.

Mader, B. T., Schauer, J. J., Seinfeld, J. H., Flagan, R. C., Yu, J. Z., Yang, H., Lim, H.-J., Turpin, B. J., Deminter, J. T., Heidemann, G., Bae, M. S., Quinn, P., Bates, T., Eatough, D. J., Huebert, B. J., Bertram, T., and Howell, S.: Sampling methods used for the collection of particle-phase organic and elemental carbon during ACE-Asia, Atmos. Environ., 37(11), 1435-1449, 2003.

Mader, B. T., Yu, J. Z., Xu, J. H., Li, Q. F., Wu, W. S., Flagan, R. C., and Seinfeld, J. H.: Molecular composition of the water-soluble fraction of atmospheric carbonaceous aerosols collected during ACE-Asia, J. Geophys. Res., 109(D6), D06206, doi:10.1029/2003JD004105, 2004.

Maenhaut, W., Raes, N., Cafmeyer, J., and Artaxo, P.: Study of elemental mass size distributions in Amazonia during the LBA/CLAIRE/SMOCC-2002 campaign, Proceedings of the 10th International Conference on Particle Induced X-ray Emission and its Analytical Applications, Portoroz, Slovenia, 2004.

Mason, B. and Moore, C. B.: Principles of Geochemistry, Hoboken, N.J., John Wiley, 1982.

Mayol-Bracero, O. L., Guyon, P., Graham, B., Roberts, G., Andreae, M. O., Decesari, S., Facchini, M. C., Fuzzi, S., and Artaxo, P.: Water-soluble organic compounds in biomass burning aerosols over Amazonia - 2. Apportionment of the chemical composition and importance of the polyacidic fraction, J. Geophys. Res., 107(D20), 8091, doi:10.1029/2001JD000522, 2002.

Mochida, M., Kawamura, K., Umemoto, N., Kobayashi, M., Matsunaga, S., Lim, H. J., Turpin, B. J., Bates, T. S., and Simoneit, B. R. T.: Spatial distributions of oxygenated organic compounds (dicarboxylic acids, fatty acids, and levoglucosan) in marine aerosols over the western Pacific and off the coast of East Asia: Continental outflow of organic aerosols during the ACE-Asia campaign, J. Geophys. Res., 108(D23), 8638, doi:10.1029/2002JD003249, 2003.

Narukawa, M., Kawamura, K., Takeuchi, N., and Nakajima, T.: Distribution of dicarboxylic acids and carbon isotopic compositions in aerosols from 1997 Indonesian forest fires, Geophys. Res. Lett., 26(20), 3101-3104, 1999.

Nenes, A., Charlson, R. J., Facchini, M. C., Kulmala, M., Laaksonen, A., and Seinfeld, J. H.: Can chemical effects on cloud droplet number rival the first indirect effect?, Geophys. Res. Lett., 29(17), 1848, doi:10.1029/2002GL015295, 2002.

Neususs, C., Gnauk, T., Plewka, A., Herrmann, H., and Quinn, P. K.: Carbonaceous aerosol over the Indian Ocean: OC/EC fractions and selected specifications from sizesegregated onboard samples, J. Geophys. Res., 107(D19), 8031, doi:10.1029/2001JD000327, 2002.

Novakov, T., Hegg, D. A., and Hobbs, P. V.: Airborne measurements of carbonaceous aerosols on the East Coast of the United States, J. Geophys. Res., 102(D25), 30 023-30030, 1997.

Pathak, R. K., Yao, X. H., and Chan, C. K.: Sampling artifacts of acidity and ionic species in PM2.5, Environ. Sci. Technol., 38(1), 
254-259, 2004.

Prenni, A. J., DeMott, P. J., Kreidenweis, S. M., Sherman, D. E., Russell, L. M., and Ming, Y.: The effects of low molecular weight dicarboxylic acids on cloud formation, J. Phys. Chem. A, 105(50), 11 240-11248, 2001.

Puxbaum, H., Rendl, J., Allabashi, R., Otter, L., and Scholes, M. C.: Mass balance of the atmospheric aerosol in a South African subtropical savanna (Nylsvley, May 1997), J. Geophys. Res., 105(D16), 20 697-20 706, 2000.

Ramanathan, V., Crutzen, P. J., Kiehl, J. T., and Rosenfeld, D.: Atmosphere - Aerosols, climate, and the hydrological cycle, Science, 294(5549), 2119-2124, 2001.

Roberts, G. C., Nenes, A., Seinfeld, J. H., and Andreae, M. O.: Impact of biomass burning on cloud properties in the Amazon Basin, J. Geophys. Res., 108(D2), 4062, doi:10.1029/2001JD000985, 2003.

Ruellan, S., Cachier, H., Gaudichet, A., Masclet, P., and Lacaux, J. P.: Airborne aerosols over central Africa during the experiment for regional sources and sinks of oxidants (EXPRESSO), J. Geophys. Res., 104(D23), 30 673-30 690, 1999.

Salma, I., Chi, X. G., and Maenhaut, W.: Elemental and organic carbon in urban canyon and background environments in Budapest, Hungary, Atmos. Environ., 38(1), 27-36, 2004.

Saxena, P. and Hildemann, L. M.: Water-soluble organics in atmospheric particles: A critical review of the literature and application of thermodynamics to identify candidate compounds, J. Atmos. Chem., 24(1), 57-109, 1996.

Schkolnik, G., Falkovich, A. H., Rudich, Y., Maenhaut, W., and Artaxo, P.: A new analytical method for the determination of levoglucosan, polyhydroxy compounds and 2-methylerythritol and its application to smoke and rainwater samples, Environ. Sci. Technol., in press, 2005.

Seinfeld, J. H. and Pandis, S. N.: Atmospheric Chemistry \& Physics: From air pollution to climate change, John Wiley \& Sons, 1997.

Sherwood, S.: A microphysical connection among biomass burning, cumulus clouds, and stratospheric moisture, Science, 295, 1272-1275, 2002.
Simoneit, B. R. T.: Biomass burning - A review of organic tracers for smoke from incomplete combustion, Appl. Geochem., 17(3), 129-162, 2002.

Simoneit, B. R. T., Schauer, J. J., Nolte, C. G., Oros, D. R., Elias, V. O., Fraser, M. P., Rogge, W. F., and Cass, G. R.: Levoglucosan, a tracer for cellulose in biomass burning and atmospheric particles, Atmos. Environ., 33(2), 173-182, 1999.

Song, C. H. and Carmichael, G. R.: Gas-particle partitioning of nitric acid modulated by alkaline aerosol, J. Atmos. Chem., 40(1), $1-22,2001$.

Tabazadeh, A., Jacobson, M. Z., Singh, H. B., Toon, O. B., Lin, J. S., Chatfield, B., Thakur, A. N., and Talbot, R. W.: Nitric acid scavenging by mineral and biomass burning aerosols, Geophys. Res. Lett., 25, 4185-4188, 1998.

Trebs, I., Meixner, F. X., Slanina, J., Otjes, R., Jongejan, P., and Andreae, M. O.: Real-time measurements of ammonia, acidic trace gases and water-soluble inorganic aerosol species at a rural site in the Amazon Basin, Atmos. Chem. Phys., 4, 967-987, 2004, SRef-ID: 1680-7324/acp/2004-4-967.

Trebs, I., Metzger, S., Meixner, F. X., Helas, G., Hoffer, A., Andreae, M. O., Moura, M. A. L., daSilva Jr., R. S., Slanina, J., Rudich, Y., Falkovich, A. H., and Artaxo, P.: The $\mathrm{NH}_{4}^{+} \mathrm{NO}_{3}^{-}$ $\mathrm{Cl}^{-} \mathrm{SO}_{4}^{2-} \mathrm{H}_{2} \mathrm{O}$ aerosol system and its gas phase precursors at a rural site in the Amazon Basin: How relevant are crustal species and soluble organic compounds?, J. Geophys. Res., in press, 2005.

Turpin, B. J., Saxena, P., and Andrews, E.: Measuring and simulating particulate organics in the atmosphere: problems and prospects, Atmos. Environ., 34(18), 2983-3013, 2000.

Yamasoe, M. A., Artaxo, P., Miguel, A. H., and Allen, A. G.: Chemical composition of aerosol particles from direct emissions of vegetation fires in the Amazon Basin: water-soluble species and trace elements, Atmos. Environ., 34(10), 1641-1653, 2000.

Yu, S. C.: Role of organic acids (formic, acetic, pyruvic and oxalic) in the formation of cloud condensation nuclei $(\mathrm{CCN})$ : a review, Atmos. Res., 53(4), 185-217, 2000. 